\title{
Strong convergence theorems for generalized equilibrium, variational inequalities and nonlinear operators
}

\begin{abstract}
A new iterative scheme is introduced to approximate a common element of the solution set of a generalized mixed equilibrium problem, the solution set of a variational inequality problem, the set of common fixed points of two countable families of weak relatively nonexpansive mappings and the set of zeros of a maximal monotone operator in Banach spaces. The results obtained in this paper generalize and improve upon some existing results in recent literature.
\end{abstract}

Mathematics Subject Classification (2010) 47H09 · 65J15 • 47J25 • 47J20 • 49N45

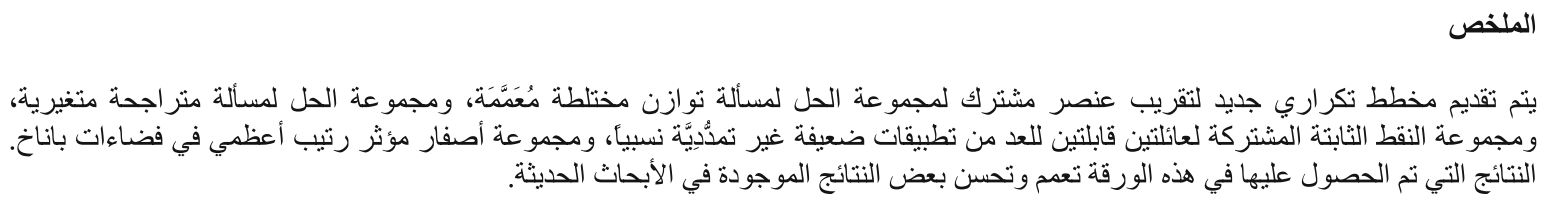

\section{Introduction}

Equilibrium problems influence the development of several branches of pure and applied sciences [2]. It has been shown that the theory of equilibrium problems provides a novel and unified treatment of a wide class of problems, which arise in economics, finance, physics, image reconstruction, ecology, transportation, network, elasticity and optimization.

Let $E$ be a real Banach space with dual $E^{*}$ and let $C$ be a nonempty closed convex subset of $E$. Let $\Theta: C \times C \rightarrow \mathbb{R}$ be a bifunction, $\varphi: C \rightarrow \mathbb{R}$ be a real valued function. A generalized mixed equilibrium

Y. Wang

Department of Mathematics, Shaoxing University, Shaoxing 312000, China

E-mail: wangyaqin0579@126.com

Y. Wang

College of Mathematics, Sichuan University, Chengdu 610064, Sichuan, China

H.-K. Xu (区)

Department of Applied Mathematics, National Sun Yat-sen University, Kaohsiung 80424, Taiwan

E-mail: xuhk@math.nsysu.edu.tw

X. Yin

Department of Mathematics, East China University of Science and Technology, Shanghai 200237, China

E-mail: yin_ximing@yahoo.com.cn 
problem (GMEP) [23] is formulated as finding a point $x \in C$ such that

$$
\Theta(x, y)+\varphi(y)-\varphi(x)+\langle A x, y-x\rangle \geq 0, \quad \forall y \in C
$$

where $A: C \rightarrow E^{*}$ is some nonlinear operator. Here are some special cases of Problem (1.1).

If $A=0$, then Problem (1.1) is reduced to the following mixed equilibrium problem [5] of finding $x \in C$ such that

$$
\Theta(x, y)+\varphi(y)-\varphi(x) \geq 0, \quad \forall y \in C .
$$

The set of solutions of this problem is denoted by MEP.

If $\varphi=0$, then Problem (1.1) is reduced to the following generalized equilibrium problem [18] of finding $x \in C$ such that

$$
\Theta(x, y)+\langle A x, y-x\rangle \geq 0, \quad \forall y \in C .
$$

If $\varphi=0$ and $A=0$, then Problem (1.1) is reduced to the following equilibrium problem of finding $x \in C$ such that

$$
\Theta(x, y) \geq 0, \quad \forall y \in C .
$$

The set of solutions of Problem (1.2) is denoted by EP.

If $\Theta=0$ and $\varphi=0$, then Problem (1.1) is reduced to the following classical variational inequality problem of finding $x \in C$ such that

$$
\langle A x, y-x\rangle \geq 0, \quad \forall y \in C .
$$

The set of solutions of Problem (1.3) is denoted by $\operatorname{VI}(C, A)$.

The problem (1.1) is general in the sense that it includes, as special cases, numerous problems in physics, optimization, variational inequalities, minimax problems, the Nash equilibrium problem in noncooperative games and others; see, for instance, [2,5,18-21].

The normalized duality mapping from $E$ to $2^{E^{*}}$ defined by

$$
J x=\left\{f \in E^{*}:\langle x, f\rangle=\|x\|^{2}=\|f\|^{2}\right\}, \quad x \in E,
$$

where $\langle\cdot, \cdot\rangle$ denotes the generalized duality pairing between $E$ and $E^{*}$. It is well known that if $E$ is smooth then $J$ is single-valued, and if $E$ is uniformly smooth then $J$ is uniformly continuous on bounded subsets of $E$ in the norm-to-norm topology. Moreover, if $E$ is a reflexive and strictly convex Banach space with a strictly convex dual $E^{*}$, then $J^{-1}$ is single-valued, one-to-one, surjective, and it is the duality mapping from $E^{*}$ into $E$ and thus $J^{-1}=I_{E^{*}}$ and $J^{-1} J=I_{E}$ (see [17]).

On the other hand, let $W: E \rightrightarrows E^{*}$ be a set-valued mapping. The problem of finding $v \in E$ satisfying $0 \in W v$ contains numerous problems in economics, optimization and physics. Such $v \in E$ is called a zero of $W$.

A set-valued mapping $W: E \rightrightarrows E^{*}$ with graph $G(W)=\left\{\left(x, x^{*}\right): x^{*} \in W x\right\}$, domain $D(W)=\{x \in$ $E: W x \neq \emptyset\}$, and range $R(W)=\cup\{W x: x \in D(W)\}$ is said to be monotone if $\left\langle x-y, x^{*}-y^{*}\right\rangle \geq 0$ for all $x^{*} \in W x, y^{*} \in W y$. A monotone operator $W$ is said to be maximal monotone if the graph $G(W)$ of $W$ is not properly contained in the graph of any other monotone operator. It is known that a monotone $W$ is a maximal monotone if and only if $R(J+r W)=E^{*}$ for all $r>0$ when $E$ is a reflexive, strictly convex and smooth Banach space (see [13]).

Let $E$ be a smooth, strictly convex and reflexive Banach space, let $C$ be a nonempty closed convex subset of $E$ and $W: E \rightrightarrows E^{*}$ be a monotone operator satisfying $D(W) \subset C \subset J^{-1}\left(\cap_{r>0} R(J+r W)\right)$. Then the resolvent of $W$ defined by $J_{r}=(J+r W)^{-1} J$ is a single-valued mapping from $E$ to $D(W)$ for all $r>0$. For $r>0$, the Yosida approximation of $W$ is defined by $W_{r} x=\left(J x-J J_{r} x\right) / r$ for all $x \in E$.

Let $A: C \rightarrow E^{*}$ be a single-valued mapping. Recall that $A$ is monotone if, for each $x, y \in C$,

$$
\langle x-y, A x-A y\rangle \geq 0 .
$$

We say that $A$ is $\gamma$-inverse strongly monotone $(\gamma$-ism) if there exists a positive real number $\gamma>0$ such that

$$
\langle x-y, A x-A y\rangle \geq \gamma\|A x-A y\|^{2}, \quad \forall x, y \in C .
$$


If $A$ is $\gamma$-ism, then it is Lipschitz continuous with constant $1 / \gamma$, i.e.,

$$
\|A x-A y\| \leq(1 / \gamma)\|x-y\|, \quad x, y \in C .
$$

Let $E$ be a smooth Banach space. The function $\phi: E \times E \rightarrow \mathbb{R}$ defined by

$$
\phi(x, y)=\|x\|^{2}-2\langle x, J y\rangle+\|y\|^{2}, \quad x, y \in E,
$$

is studied by Alber [1], Kamimura and Takahashi [7] and Reich [12]. It is not hard to find that

$$
(\|x\|-\|y\|)^{2} \leq \phi(x, y) \leq(\|x\|+\|y\|)^{2}, \quad x, y \in E .
$$

Observe that, in a Hilbert space $H, \phi(x, y)=\|x-y\|^{2}, \forall x, y \in H$.

Lemma 1.1 [1] Let $C$ be a nonempty closed and convex subset of a real reflexive, strictly convex, and smooth Banach space $E$ and let $x \in E$. Then there exists a unique element $x_{0} \in C$ such that $\phi\left(x_{0}, x\right)=\min \{\phi(z, x)$ : $z \in C\}$.

Let $E$ be a reflexive, strictly convex, and smooth Banach space and $C$ be a nonempty closed and convex subset of $E$. The generalized projection mapping, introduced by Alber [1], is a mapping $\Pi_{C}: E \rightarrow C$, that assigns to an arbitrary point $x \in E$ the minimum point of the functional $\phi(x, y)$, that is $\Pi_{C} x=x_{0}$, where $x_{0}$ is determined as in Lemma 1.1, i.e., the unique solution in $C$ to the minimization problem $\phi\left(x_{0}, x\right)=$ $\min \{\phi(z, x): z \in C\}$.

Let $T$ be a mapping from $C$ into itself. By $F(T)$ we denote the set of fixed points of $T$, i.e., $F(T)=\{x \in$ $C: T x=x\}$. A point $p$ in $C$ is said to be an asymptotic fixed point of $T$ if $C$ contains a sequence $\left\{x_{n}\right\}$ which converges weakly to $p$ such that $\lim _{n \rightarrow \infty}\left\|T x_{n}-x_{n}\right\|=0$. The set of asymptotic fixed points of $T$ will be denoted by $\widehat{F}(T)$. A mapping $T$ from $C$ into itself is called nonexpansive if $\|T x-T y\| \leq\|x-y\|$ for all $x, y \in C$, and relatively nonexpansive (see [3,4]) if $\widehat{F}(T)=F(T)$ and $\phi(p, T x) \leq \phi(p, x)$ for all $x \in C$ and $p \in F(T)$. A point $p$ in $C$ is said to be a strong asymptotic fixed point of $T$ if $C$ contains a sequence $\left\{x_{n}\right\}$ which converges strongly to $p$ such that $\lim _{n \rightarrow \infty}\left\|T x_{n}-x_{n}\right\|=0$. The set of strong asymptotic fixed points of $T$ will be denoted by $\widetilde{F}(T)$. A mapping $T$ from $C$ into itself is called relatively weak nonexpansive if $\widetilde{F}(T)=F(T)$ and $\phi(p, T x) \leq \phi(p, x)$ for all $x \in C$ and $p \in F(T)$.

When $W$ is a maximal monotone, a well-known method for solving the equation $0 \in W v$ in a Hilbert space $H$ is the proximal point algorithm (see [14]): $x_{1}=x \in H$ and

$$
x_{n+1}=J_{r_{n}} x_{n}, \quad n=1,2, \ldots,
$$

where $\left\{r_{n}\right\} \subset(0, \infty)$ and $J_{r}=(I+r W)^{-1}$ for all $r>0$ is the resolvent operator for $W$. Rockafellar [14] proved in the Hilbert space setting that the sequence $\left\{x_{n}\right\}$ converges weakly to an element of $W^{-1} 0$.

The modifications of the proximal point algorithm for different operators have been investigated by many authors. Kohsaka and Takahashi [9] considered the following algorithm (1.5) in a smooth and uniformly convex Banach space:

$$
x_{n+1}=J^{-1}\left(\beta_{n} J\left(x_{1}\right)+\left(1-\beta_{n}\right) J\left(J_{r_{n}} x_{n}\right)\right), \quad n=1,2, \ldots,
$$

and Kamimura, Kohsaka and Takahashi [8] considered the algorithm (1.6) in a uniformly smooth and uniformly convex Banach space:

$$
x_{n+1}=J^{-1}\left(\beta_{n} J\left(x_{n}\right)+\left(1-\beta_{n}\right) J\left(J_{r_{n}} x_{n}\right)\right), \quad n=1,2, \ldots
$$

They showed that the algorithm (1.5) converges strongly and the algorithm (1.6) converges weakly provided that the sequences $\left\{\beta_{n}\right\}$ and $\left\{r_{n}\right\}$ of real numbers are chosen appropriately.

Recently, Habtu and Naseer [22] introduced the following iterative scheme for finding a common element of the solution set of a variational inequality problem and a relatively weak nonexpansive mapping:

$$
\left\{\begin{array}{l}
x_{0} \in C \text { chosen arbitrarily, } \\
y_{n}=\Pi_{C} J^{-1}\left(J x_{n}-\alpha_{n} A x_{n}\right) \\
z_{n}=T y_{n} \\
H_{0}=\left\{v \in C: \phi\left(v, z_{0}\right) \leq \phi\left(v, y_{0}\right) \leq \phi\left(v, x_{0}\right)\right\} \\
H_{n}=\left\{v \in H_{n-1} \cap W_{n-1}: \phi\left(v, z_{n}\right) \leq \phi\left(v, y_{n}\right) \leq \phi\left(v, x_{n}\right)\right\} \\
W_{0}=C \\
W_{n}=\left\{v \in W_{n-1} \cap H_{n-1}:\left\langle x_{n}-v, J x_{0}-J x_{n}\right\rangle \geq 0\right\} \\
x_{n+1}=\Pi_{H_{n} \cap W_{n}} x_{0}, n \geq 0
\end{array}\right.
$$


In 2009, Takahashi and Zembayashi [19] proposed the following modification of iteration process for a relatively nonexpansive mapping:

$$
\left\{\begin{array}{l}
x_{0}=x \in C, \quad C_{0}=C, \\
y_{n}=J^{-1}\left(\alpha_{n} J x_{n}+\left(1-\alpha_{n}\right) J T x_{n}\right), \\
u_{n} \in C \text { such that } \Theta\left(u_{n}, y\right)+\frac{1}{r_{n}}\left\langle y-u_{n}, J u_{n}-J y_{n}\right\rangle \geq 0, \quad \forall y \in C, \\
C_{n}=\left\{z \in C: \phi\left(z, u_{n}\right) \leq \phi\left(z, x_{n}\right)\right\}, \\
Q_{n}=\left\{z \in C:\left\langle x_{n}-z, J x-J x_{n}\right\rangle \geq 0\right\}, \\
x_{n+1}=\Pi_{C_{n} \cap Q_{n}} x .
\end{array}\right.
$$

They proved that $\left\{x_{n}\right\}$ converges strongly to $\Pi_{F(T) \cap E P} x$.

Very recently, Wang and Zeng [20] considered the following iterative scheme for approximating a common element of the solution set of a generalized mixed equilibrium problem, the solution set of a variational inequality problem and the set of fixed points of a relatively weak nonexpansive mapping:

$$
\left\{\begin{array}{l}
x_{0} \in C, \text { chosen arbitrarily, } \\
y_{n}=\Pi_{C} J^{-1}\left(J x_{n}-\lambda_{n} A x_{n}\right), \\
z_{n}=J^{-1}\left(\beta_{n} J x_{n}+\left(1-\beta_{n}\right) J T y_{n}\right), \\
u_{n}=K_{r_{n}} z_{n}, \\
H_{0}=\left\{v \in C: \phi\left(v, u_{0}\right) \leq \beta_{0} \phi\left(v, x_{0}\right)+\left(1-\beta_{0}\right) \phi\left(v, y_{0}\right) \leq \phi\left(v, x_{0}\right)\right\}, \\
H_{n}=\left\{v \in H_{n-1} \cap W_{n-1}: \phi\left(v, u_{n}\right) \leq \beta_{n} \phi\left(v, x_{n}\right)+\left(1-\beta_{n}\right) \phi\left(v, y_{n}\right) \leq \phi\left(v, x_{n}\right)\right\}, \\
W_{0}=C, \\
W_{n}=\left\{v \in W_{n-1} \cap H_{n-1}:\left\langle x_{n}-v, J x_{0}-J x_{n}\right\rangle \geq 0\right\}, \\
x_{n+1}=\Pi_{H_{n} \cap W_{n} x_{0}, n \geq 0,}
\end{array}\right.
$$

where $K_{r_{n}}: E \rightarrow C$ is a mapping (see its definition in the statement of Lemma 2.8 in Sect. 2). Under suitable conditions, they established some strong convergence theorems.

In 2010, Su et al. [16] introduced the definitions of countable family of relatively nonexpansive mappings and countable family of weak relatively nonexpansive mappings which are generalizations of relatively nonexpansive mappings and relatively weak nonexpansive mappings respectively.

Let $C$ be a closed convex subset of $E$, and let $\left\{T_{n}\right\}_{n=0}^{\infty}$ be a countable family of mappings from $C$ into itself. Let $F\left(T_{n}\right)$ denote the set of fixed points of $T_{n}$ for all $n \geq 0$. A point $p$ in $C$ is said to be an asymptotic fixed point of $\left\{T_{n}\right\}_{n=0}^{\infty}[16]$ if $C$ contains a sequence $\left\{x_{n}\right\}$ which converges weakly to $p$ such that $\lim _{n \rightarrow \infty}\left\|x_{n}-T_{n} x_{n}\right\|=0$. The set of asymptotic fixed point of $\left\{T_{n}\right\}_{n=0}^{\infty}$ will be denoted $\widehat{F}\left(\left\{T_{n}\right\}_{n=0}^{\infty}\right)$. A point $p$ in $C$ is said to be a strong asymptotic fixed point of $\left\{T_{n}\right\}_{n=0}^{\infty}$ [16] if $C$ contains a sequence $\left\{x_{n}\right\}$ which converges strongly to $p$ such that $\lim _{n \rightarrow \infty}\left\|x_{n}-T_{n} x_{n}\right\|=0$. The set of strong asymptotic fixed points of $\left\{T_{n}\right\}_{n=0}^{\infty}$ will be denoted $\widetilde{F}\left(\left\{T_{n}\right\}_{n=0}^{\infty}\right)$.

Definition 1.2 [16] A countable family of mappings $\left\{T_{n}\right\}_{n=0}^{\infty}$ is said to be relatively nonexpansive if the following conditions are satisfied:

(1) $\cap_{n=0}^{\infty} F\left(T_{n}\right) \neq \emptyset$;

(2) $\phi\left(u, T_{n} x\right) \leq \phi(u, x), \quad \forall u \in F\left(T_{n}\right), x \in C, n \geq 0$;

(3) $\widehat{F}\left(\left\{T_{n}\right\}_{n=0}^{\infty}\right)=\cap_{n=0}^{\infty} F\left(T_{n}\right)$.

Definition 1.3 [16] Countable family of mappings $\left\{T_{n}\right\}_{n=0}^{\infty}$ is said to be weak relatively nonexpansive if the following conditions are satisfied:

(1) $\cap_{n=0}^{\infty} F\left(T_{n}\right) \neq \emptyset$;

(2) $\phi\left(u, T_{n} x\right) \leq \phi(u, x), \quad \forall u \in F\left(T_{n}\right), x \in C, n \geq 0$;

(3) $\widetilde{F}\left(\left\{T_{n}\right\}_{n=0}^{\infty}\right)=\bigcap_{n=0}^{\infty} F\left(T_{n}\right)$.

It is obvious that a countable family of relatively nonexpansive mappings is a countable family of weak relatively nonexpansive mappings. In fact, for any countable family of mappings $\left\{T_{n}\right\}_{n=0}^{\infty}$, we have $\cap_{n=0}^{\infty} F\left(T_{n}\right) \subset$ $\widetilde{F}\left(\left\{T_{n}\right\}_{n=0}^{\infty}\right) \subset \widehat{F}\left(\left\{T_{n}\right\}_{n=0}^{\infty}\right)$. Therefore, if $\left\{T_{n}\right\}_{n=0}^{\infty}$ is a countable family of relatively nonexpansive mappings, then $\cap_{n=0}^{\infty} F\left(T_{n}\right)=\widetilde{F}\left(\left\{T_{n}\right\}_{n=0}^{\infty}\right)=\widehat{F}\left(\left\{T_{n}\right\}_{n=0}^{\infty}\right)$. But there is a countable family of weak relatively nonexpansive mappings which is not a countable family of relatively nonexpansive mappings (see [16]). Moreover they established the following convergence theorems: 
Theorem SXZ1 [16] Let $E$ be a uniformly convex and uniformly smooth real Banach space, let $C$ be a nonempty closed convex subset of $E$, let $\left\{T_{n}\right\},\left\{S_{n}\right\}$ be two countable families of weak relatively nonexpansive mappings from $C$ into itself such that $F:=\left(\cap_{n=0}^{\infty} F\left(T_{n}\right)\right) \cap\left(\cap_{n=0}^{\infty} F\left(S_{n}\right)\right) \neq \emptyset$. Define a sequence $\left\{x_{n}\right\}$ in $C$ by the following algorithm:

$$
\left\{\begin{array}{l}
x_{0} \in C, \text { chosen arbitrarily, } \\
z_{n}=J^{-1}\left(\beta_{n}^{(1)} J x_{n}+\beta_{n}^{(2)} J T_{n} x_{n}+\beta_{n}^{(3)} J S_{n} x_{n}\right) \\
y_{n}=J^{-1}\left(\alpha_{n} J x_{n}+\left(1-\alpha_{n}\right) J z_{n}\right) \\
C_{n}=\left\{z \in C_{n-1} \cap Q_{n-1}: \phi\left(z, y_{n}\right) \leq \phi\left(z, x_{n}\right)\right\} \\
C_{0}=\left\{z \in C: \phi\left(v, y_{0}\right) \leq \phi\left(v, x_{0}\right)\right\} \\
Q_{n}=\left\{z \in Q_{n-1} \cap Q_{n-1}:\left\langle x_{n}-v, J x_{0}-J x_{n}\right\rangle \geq 0\right\} \\
Q_{0}=C \\
x_{n+1}=\Pi_{C_{n} \cap Q_{n}} x_{0}, n \geq 0
\end{array}\right.
$$

with the conditions:

(i) $\lim \inf _{n \rightarrow \infty} \beta_{n}^{(1)} \beta_{n}^{(2)}>0$;

(ii) $\liminf _{n \rightarrow \infty} \beta_{n}^{(1)} \beta_{n}^{(3)}>0$;

(iii) $0 \leq \alpha_{n} \leq \alpha<1$ for some $\alpha \in(0,1)$.

Then $\left\{x_{n}\right\}$ converges strongly to $\Pi_{F} x_{0}$, where $\Pi_{F}$ is the generalized projection from $C$ onto $F$.

Theorem SXZ2 [16] Let $E$ be a uniformly convex and uniformly smooth real Banach space, let $C$ be a nonempty closed convex subset of $E$, let $\left\{T_{n}\right\},\left\{S_{n}\right\}$ be two countable families of weak relatively nonexpansive mappings from $C$ into itself such that $F:=\left(\cap_{n=0}^{\infty} F\left(T_{n}\right)\right) \cap\left(\cap_{n=0}^{\infty} F\left(S_{n}\right)\right) \neq \emptyset$. Define a sequence $\left\{x_{n}\right\}$ in $C$ by the following algorithm:

$$
\left\{\begin{aligned}
x_{0} \in C, \text { chosen arbitrarily, } \\
z_{n}=J^{-1}\left(\beta_{n}^{(1)} J x_{0}+\beta_{n}^{(2)} J T_{n} x_{n}+\beta_{n}^{(3)} J S_{n} x_{n}\right), \\
y_{n}=J^{-1}\left(\alpha_{n} J x_{n}+\left(1-\alpha_{n}\right) J z_{n}\right), \\
C_{n}=\left\{z \in C_{n-1} \cap Q_{n-1}:\right. \\
\left.\quad \phi\left(z, y_{n}\right) \leq\left(1-\alpha_{n} \beta_{n}^{(1)}\right) \phi\left(z, x_{n}\right)+\alpha_{n} \beta_{n}^{(1)} \phi\left(z, x_{0}\right)\right\}, \\
C_{0}=\left\{z \in C: \phi\left(v, y_{0}\right) \leq \phi\left(v, x_{0}\right)\right\}, \\
Q_{n}=\left\{z \in Q_{n-1} \cap Q_{n-1}:\left\langle x_{n}-v, J x_{0}-J x_{n}\right\rangle \geq 0\right\}, \\
Q_{0}=C, \\
x_{n+1}=\Pi_{C_{n} \cap Q_{n}} x_{0}, n \geq 0,
\end{aligned}\right.
$$

with the conditions:

(i) $\lim _{n \rightarrow \infty} \beta_{n}^{(1)}=0$;

(ii) $\lim \sup _{n \rightarrow \infty} \beta_{n}^{(1)} \beta_{n}^{(3)}>0$;

Then $\left\{x_{n}\right\}$ converges strongly to $\Pi_{F} x_{0}$, where $\Pi_{F}$ is the generalized projection from $C$ onto $F$.

Motivated and inspired by the above work, we are aimed in this paper at introducing a new hybrid projection iterative scheme which will be proved to converge strongly to a common element of the solution set of a generalized mixed equilibrium problem, the solution set of a variational inequality problem and the set of common fixed points of two countable families of weak relatively nonexpansive mappings in Banach spaces. Our results improve and generalize many existing results in current literature.

\section{Preliminaries}

Let $E$ be a real normed linear space. The modulus of smoothness of $E$ is the function $\rho_{E}:[0,+\infty) \rightarrow[0,+\infty)$ defined by

$$
\rho_{E}(\tau):=\sup \left\{\frac{\|x+y\|+\|x-y\|}{2}-1:\|x\|=1,\|y\|=\tau\right\}
$$


The space $E$ is said to be smooth if $\rho_{E}(\tau)>0, \forall \tau>0$, and $E$ is called uniformly smooth if and only if $\lim _{t \rightarrow 0^{+}} \frac{\rho_{E}(t)}{t}=0$.

The modulus of convexity of $E$ is the function $\delta_{E}:(0,2] \rightarrow[0,1]$ defined by

$$
\delta_{E}(\varepsilon):=\inf \left\{1-\left\|\frac{x+y}{2}\right\|:\|x\|=\|y\|=1, \varepsilon=\|x-y\|\right\} .
$$

$E$ is called uniformly convex if and only if $\delta_{E}(\varepsilon)>0$ for every $\varepsilon \in(0,2]$. Let $p>1$; then $E$ is said to be $p$-uniformly convex if there exists a constant $c>0$ such that $\delta_{E}(\varepsilon) \geq c \varepsilon^{p}$ for every $\varepsilon \in(0,2]$. Observe that every $p$-uniformly convex is uniformly convex. It is well known (see for example [21]) that

$$
L_{p}\left(l_{p}\right) \text { or } W_{m}^{p} \text { is }\left\{\begin{array}{l}
p \text {-uniformly convex if } p \geq 2 \\
2 \text { - uniformly convex if } 1<p \leq 2
\end{array}\right.
$$

In what follows, we shall make use of the following lemmas.

Lemma 2.1 [21] Let $E$ be a 2-uniformly convex and smooth Banach space. Then, for all $x, y \in E$, we have

$$
\|x-y\| \leq \frac{2}{c^{2}}\|J x-J y\|,
$$

where $J$ is the normalized duality mapping of $E$ and $1 / c(0<c \leq 1)$ is the 2-uniform convexity constant of $E$.

Lemma 2.2 [1,7] Let $E$ be a real smooth, strictly convex, and reflexive Banach space and $C$ be a nonempty closed convex subset. Then the following conclusions hold:

(1) $\phi\left(y, \Pi_{C} x\right)+\phi\left(\Pi_{C} x, x\right) \leq \phi(y, x)$ for all $x \in E, y \in C$,

(2) Suppose $x \in E$ and $z \in C$, then

$$
z=\Pi_{C} x \quad \Leftrightarrow \quad\langle z-y, J x-J z\rangle \geq 0, \quad \forall y \in C .
$$

Lemma 2.3 [7] Let $E$ be a real smooth and uniformly convex Banach space and let $\left\{x_{n}\right\}$ and $\left\{y_{n}\right\}$ be two sequences of E. If either $\left\{x_{n}\right\}$ or $\left\{y_{n}\right\}$ is bounded and $\phi\left(x_{n}, y_{n}\right) \rightarrow 0$ as $n \rightarrow \infty$, then $x_{n}-y_{n} \rightarrow 0$ as $n \rightarrow \infty$.

Lemma 2.4 [11] Let $E$ be a real smooth Banach space and let $A: E \rightrightarrows E^{*}$ be a maximal monotone mapping. Then $A^{-1}(0)$ is a closed and convex subset of $E$.

We denote by $N_{C}(v)$ the normal cone to $C$ at a point $v \in C$, that is

$$
N_{C}(v):=\left\{x^{*} \in E^{*}:\left\langle v-y, x^{*}\right\rangle \geq 0, \quad y \in C\right\} .
$$

In the following, we shall use the following Lemma.

Lemma 2.5 [14] Let $C$ be a nonempty closed convex subset of a Banach space $E$ and let $A$ be a monotone and hemicontinuous operator of $C$ into $E^{*}$. Let $T \subset E \times E^{*}$ be the operator defined by

$$
T v:= \begin{cases}A v+N_{C}(v), & \text { if } v \in C, \\ \varnothing, & \text { if } v \notin C .\end{cases}
$$

Then $T$ is maximal monotone and $T^{-1} 0=\operatorname{VI}(C, A)$.

We will make use of the function $V: E \times E^{*} \rightarrow \mathbb{R}$ defined by [1]

$$
V\left(x, x^{*}\right)=\|x\|^{2}-2\left\langle x, x^{*}\right\rangle+\|x\|^{2}, \quad x \in E, x^{*} \in E^{*} .
$$

That is, $V\left(x, x^{*}\right)=\phi\left(x, J^{-1} x^{*}\right)$ for all $x \in E$ and $x^{*} \in E^{*}$. We know the following Lemma.

Lemma 2.6 [1] Let E be a reflexive strictly convex and smooth Banach space. Then

$$
V\left(x, x^{*}\right)+2\left\langle J^{-1} x^{*}-x, y^{*}\right\rangle \leq V\left(x, x^{*}+y^{*}\right), \quad x \in E, x^{*}, y^{*} \in E^{*} .
$$

The following inequality is an extension to an inequality established in [21]. 
Lemma 2.7 [6] Let $E$ be a uniformly convex Banach space and $B_{r}(0)=\{x \in E:\|x\| \leq r\}$ be a closed ball of $E$. Then there exists a continuous strictly increasing convex function $g:[0, \infty) \rightarrow[0, \infty)$ with $g(0)=0$ such that

$$
\|\lambda x+\mu y+\gamma z\|^{2} \leq \lambda\|x\|^{2}+\mu\|y\|^{2}+\gamma\|z\|^{2}-\lambda \mu g(\|x-y\|)
$$

for all $x, y, z \in B_{r}(0)$ and $\lambda, \mu, \gamma \in[0,1]$ with $\lambda+\mu+\gamma=1$.

For solving the equilibrium problem, let us assume that $\Theta$ satisfies the following conditions:

(A1) $\Theta(x, x)=0$ for all $x \in C$;

(A2) $\Theta$ is monotone, i.e., $\Theta(x, y)+\Theta(y, x) \leq 0$ for all $x, y \in C$;

(A3) for each $x, y, z \in C$,

$$
\lim _{t \rightarrow 0} \Theta(t z+(1-t) x, y) \leq \Theta(x, y)
$$

(A4) for each $x \in C, y \mapsto \Theta(x, y)$ is convex and lower semi-continuous.

Lemma 2.8 [23] Let $C$ be a closed subset of a smooth, strictly convex and reflexive Banach space E. Let $B: C \rightarrow E^{*}$ be a continuous and monotone mapping, $\varphi: C \rightarrow \mathbb{R}$ be a lower semi-continuous and convex function, and $\Theta: C \times C \rightarrow \mathbb{R}$ be a bifunction satisfying (A1)-(A4). Then, for $r>0$ and $x \in E$, there exists $u \in C$ such that

$$
\Theta(u, y)+\langle B u, y-u\rangle+\varphi(y)-\varphi(u)+\frac{1}{r}\langle y-u, J u-J x\rangle \geq 0, \quad \forall y \in C .
$$

Define a mapping $K_{r}: E \rightarrow C$ by

$$
K_{r}(x):=\left\{u \in C: \Theta(u, y)+\langle B u, y-u\rangle+\varphi(y)-\varphi(u)+\frac{1}{r}\langle y-u, J u-J x\rangle \geq 0, \forall y \in C\right\}
$$

for all $x \in E$. Then, the following conclusions hold:

(1) $K_{r}$ is single-valued;

(2) $K_{r}$ is firmly nonexpansive, i.e., for all $x, y \in E$,

$$
\left\langle K_{r} x-K_{r} y, J K_{r} x-J K_{r} y\right\rangle \leq\left\langle K_{r} x-K_{r} y, J x-J y\right\rangle ;
$$

(3) $F\left(K_{r}\right)=G M E P$;

(4) GMEP is closed and convex;

(5) $\phi\left(p, K_{r} z\right)+\phi\left(K_{r} z, z\right) \leq \phi(p, z), \forall p \in F\left(K_{r}\right), z \in E$.

Lemma 2.9 [10] Let $E$ be a smooth, strictly convex and reflexive Banach space, let $C$ be a nonempty closed convex subset of $E$, and let $W: E \rightrightarrows E^{*}$ be a monotone operator satisfying $D(W) \subset C \subset J^{-1}\left(\cap_{r>0} R(J+r W)\right)$. Let $r>0$, let $J_{r}$ and $W_{r}$ be the resolvent and the Yosida approximation of $W$, respectively. Then the following hold:

(i) $\phi\left(u, J_{r} x\right)+\phi\left(J_{r} x, x\right) \leq \phi(u, x)$, for all $x \in C, u \in W^{-1} 0$;

(ii) $\left(J_{r} x, W_{r} x\right) \in G(W)$, for all $x \in C$;

(iii) $F\left(J_{r}\right)=W^{-1} 0$.

\section{Strong convergence theorems}

Theorem 3.1 Let $E$ be a real uniformly smooth and 2-uniformly convex Banach space (e.g., $L^{p}$ for $\left.1<p \leq 2\right)$ and $C$ be a nonempty, closed and convex subset of $E$. Let $W: E \rightrightarrows E^{*}$ be a maximal monotone operator satisfying $D(W) \subset C$ and let $J_{t}=(J+t W)^{-1} J$ for all $t>0$. Let $A: C \rightarrow E^{*}$ be a $\gamma$-inverse strongly monotone mapping, $B: C \rightarrow E^{*}$ be a monotone continuous mapping. Let $\left\{T_{n}\right\},\left\{S_{n}\right\}$ be two countable families of weak relatively nonexpansive mappings from $C$ into itself such that $\Omega:=\left(\cap_{n=0}^{\infty} F\left(T_{n}\right)\right) \cap\left(\cap_{n=0}^{\infty} F\left(S_{n}\right)\right) \cap$ $\operatorname{VI}(C, A) \cap G M E P \cap W^{-1} 0 \neq \emptyset$. Assume that $\|A x\| \leq\|A x-A p\|$ for all $x \in C$ and $p \in \operatorname{VI}(C, A)$. 
Suppose that $0<a<\lambda_{n}<b:=c^{2} \gamma / 2$, where $c$ is the constant in (2.1). Let $\left\{r_{n}\right\} \subset\left[c^{*},+\infty\right)$ for some $c^{*}>0$ and $\left\{t_{n}\right\} \subset(0,+\infty)$ satisfy $\lim _{n \rightarrow \infty} t_{n}>0$. Let $\left\{x_{n}\right\}$ be the sequence generated by

$$
\left\{\begin{array}{l}
x_{0} \in C, \text { chosen arbitrarily, } \\
v_{n}=\Pi_{C} J^{-1}\left(J x_{n}-\lambda_{n} A x_{n}\right), \\
z_{n}=J^{-1}\left(\beta_{n}^{(1)} J x_{n}+\beta_{n}^{(2)} J T_{n} J_{t_{n}} v_{n}+\beta_{n}^{(3)} J S_{n} v_{n}\right), \\
y_{n}=J^{-1}\left(\alpha_{n} J x_{n}+\left(1-\alpha_{n}\right) J z_{n}\right) \\
u_{n}=K_{r_{n}} y_{n}, \\
C_{0}=\left\{z \in C: \phi\left(z, u_{0}\right) \leq \phi\left(z, x_{0}\right)\right\}, \\
C_{n}=\left\{z \in C_{n-1} \cap Q_{n-1}: \phi\left(z, u_{n}\right) \leq \phi\left(z, x_{n}\right)\right\}, \\
Q_{0}=C, \\
Q_{n}=\left\{z \in C_{n-1} \cap Q_{n-1}:\left\langle x_{n}-z, J x_{0}-J x_{n}\right\rangle \geq 0\right\}, \\
x_{n+1}=\Pi_{C_{n} \cap Q_{n} x_{0}, n \geq 0,},
\end{array}\right.
$$

where $J$ is the normalized duality mapping, $\left\{\beta_{n}^{(1)}\right\},\left\{\beta_{n}^{(2)}\right\},\left\{\beta_{n}^{(3)}\right\}$ and $\left\{\alpha_{n}\right\}$ are four sequences in [0, 1] satisfying $\beta_{n}^{(1)}+\beta_{n}^{(2)}+\beta_{n}^{(3)}=1$ for all $n \geq 0$, and, in addition, the following conditions:

(i) $\liminf _{n \rightarrow \infty} \beta_{n}^{(1)} \beta_{n}^{(2)}>0$;

(ii) $\liminf _{n \rightarrow \infty} \beta_{n}^{(1)} \beta_{n}^{(3)}>0$;

(iii) $\limsup _{n \rightarrow \infty} \alpha_{n}<1$ and $\lim _{\sup } \operatorname{sum}_{n \rightarrow \infty} \beta_{n}^{(1)}<1$.

Then $\left\{x_{n}\right\}$ converges strongly to $\Pi_{\Omega} x_{0}$.

Proof We divide the proof into four steps.

Step 1 First we prove that $\Omega \subset C_{n} \cap Q_{n}, \forall n \geq 0$.

In fact, it is obvious that $\Omega$ is closed and convex and it follows from the definitions of $C_{n}$ and $Q_{n}$ that they both are closed and convex for each $n \geq 0$. Next, we prove by induction that $\Omega \subset C_{n} \cap Q_{n}$ for all $n \geq 0$. Observe that $\Omega \subset Q_{0}=C$. Let $w_{n}=J_{t_{n}} v_{n}$, for any given $p \in \Omega$, from the definition of $\phi(x, y)$ and the convexity of $\|\cdot\|^{2}$, we have

$$
\begin{aligned}
\phi\left(p, y_{0}\right)= & \phi\left(p, J^{-1}\left(\alpha_{0} J x_{0}+\left(1-\alpha_{0}\right) J z_{0}\right)\right) \\
= & \|p\|^{2}-2\left\langle p, \alpha_{0} J x_{0}+\left(1-\alpha_{0}\right) J z_{0}\right\rangle+\left\|\alpha_{0} J x_{0}+\left(1-\alpha_{0}\right) J z_{0}\right\|^{2} \\
\leq & \alpha_{0} \phi\left(p, x_{0}\right)+\left(1-\alpha_{0}\right) \phi\left(p, z_{0}\right) \\
\phi\left(p, z_{0}\right)= & \phi\left(p, J^{-1}\left(\beta_{0}^{(1)} J x_{0}+\beta_{0}^{(2)} J T_{0} w_{0}+\beta_{0}^{(3)} J S_{0} v_{0}\right)\right) \\
= & \left.\|p\|^{2}-2\left\langle p, \beta_{0}^{(1)} J x_{0}+\beta_{0}^{(2)} J T_{0} w_{0}+\beta_{0}^{(3)} J S_{0} v_{0}\right)\right\rangle \\
& \left.+\| \beta_{0}^{(1)} J x_{0}+\beta_{0}^{(2)} J T_{0} w_{0}+\beta_{0}^{(3)} J S_{0} v_{0}\right) \|^{2} \\
\leq & \beta_{0}^{(1)} \phi\left(p, x_{0}\right)+\beta_{0}^{(2)} \phi\left(p, T_{0} w_{0}\right)+\beta_{0}^{(3)} \phi\left(p, S_{0} v_{0}\right) \\
\leq & \beta_{0}^{(1)} \phi\left(p, x_{0}\right)+\beta_{0}^{(2)} \phi\left(p, w_{0}\right)+\beta_{0}^{(3)} \phi\left(p, v_{0}\right) .
\end{aligned}
$$

Moreover it follows from Lemmas 2.2 and 2.6 that

$$
\begin{aligned}
\phi\left(p, v_{0}\right) \leq & \phi\left(p, J^{-1}\left(J x_{0}-\lambda_{0} A x_{0}\right)\right) \\
\leq & V\left(p, J x_{0}-\lambda_{0} A x_{0}\right) \\
\leq & V\left(p, J x_{0}-\lambda_{0} A x_{0}+\lambda_{0} A x_{0}\right)-2\left\langle J^{-1}\left(J x_{0}-\lambda_{0} A x_{0}\right)-p, \lambda_{0} A x_{0}\right\rangle \\
= & \phi\left(p, x_{0}\right)-2 \lambda_{0}\left\langle x_{0}-p, A x_{0}-A p\right\rangle-2 \lambda_{0}\left\langle x_{0}-p, A p\right\rangle \\
& -2 \lambda_{0}\left\langle J^{-1}\left(J x_{0}-\lambda_{0} A x_{0}\right)-x_{0}, A x_{0}\right\rangle .
\end{aligned}
$$


Since $p \in \operatorname{VI}(C, A), A$ is $\gamma$-ism, from the above inequality, Lemma 2.1 and the fact that $\|A x\| \leq\|A x-A p\|$ for all $x \in C$ and $p \in V I(C, A)$, we obtain

$$
\begin{aligned}
\phi\left(p, v_{0}\right) & \leq \phi\left(p, x_{0}\right)-2 \lambda_{0} \gamma\left\|A x_{0}-A p\right\|^{2}+2 \lambda_{0}\left\|J^{-1}\left(J x_{0}-\lambda_{0} A x_{0}\right)-x_{0}\right\|\left\|A x_{0}\right\| \\
& \leq \phi\left(p, x_{0}\right)-2 \lambda_{0} \gamma\left\|A x_{0}-A p\right\|^{2}+\frac{4}{c^{2}} \lambda_{0}^{2}\left\|A x_{0}-A p\right\|^{2} \\
& =\phi\left(p, x_{0}\right)+2 \lambda_{0}\left(\frac{2}{c^{2}} \lambda_{0}-\gamma\right)\left\|A x_{0}-A p\right\|^{2} \\
& \leq \phi\left(p, x_{0}\right) .
\end{aligned}
$$

It follows from Lemma 2.9 that

$$
\phi\left(p, w_{0}\right)=\phi\left(p, J_{t_{0}} v_{0}\right) \leq \phi\left(p, v_{0}\right)
$$

From (3.2)-(3.4), we have

$$
\phi\left(p, z_{0}\right) \leq \phi\left(p, x_{0}\right)
$$

So from (3.1) and (3.5), we have

$$
\phi\left(p, y_{0}\right) \leq \phi\left(p, x_{0}\right)
$$

By Lemma 2.8(5) and (3.6), we have

$$
\phi\left(p, u_{0}\right)=\phi\left(p, K_{r_{0}} y_{0}\right) \leq \phi\left(p, y_{0}\right) \leq \phi\left(p, x_{0}\right) .
$$

Therefore, $p \in C_{0}$ and so, $p \in C_{0} \cap Q_{0}$. Suppose $\Omega \subset C_{n-1} \cap Q_{n-1}$. Then we deduce from (3.1)-(3.7) that

$$
\begin{aligned}
\phi\left(p, w_{n}\right) & \leq \phi\left(p, v_{n}\right) \leq \phi\left(p, x_{n}\right) \\
\phi\left(p, z_{n}\right) & \leq \beta_{n}^{(1)} \phi\left(p, x_{n}\right)+\beta_{n}^{(2)} \phi\left(p, v_{n}\right)+\beta_{n}^{(3)} \phi\left(p, v_{n}\right) \\
& \leq \beta_{n}^{(1)} \phi\left(p, x_{n}\right)+\left(1-\beta_{n}^{(1)}\right)\left[\phi\left(p, x_{n}\right)-2 \lambda_{n} \gamma\left\|A x_{n}-A p\right\|^{2}+\frac{4}{c^{2}} \lambda_{n}^{2}\left\|A x_{n}-A p\right\|^{2}\right] \\
& =\phi\left(p, x_{n}\right)+\left(1-\beta_{n}^{(1)}\right) 2 \lambda_{n}\left(\frac{2}{c^{2}} \lambda_{n}-\gamma\right)\left\|A x_{n}-A p\right\|^{2} \\
& \leq \phi\left(p, x_{n}\right) \\
\phi\left(p, z_{n}\right) & \leq \beta_{n}^{(1)} \phi\left(p, x_{n}\right)+\beta_{n}^{(2)} \phi\left(p, w_{n}\right)+\beta_{n}^{(3)} \phi\left(p, v_{n}\right) \\
& \leq\left(1-\beta_{n}^{(2)}\right) \phi\left(p, x_{n}\right)+\beta_{n}^{(2)} \phi\left(p, w_{n}\right) \\
\phi\left(p, u_{n}\right) & \leq \phi\left(p, y_{n}\right) \leq \alpha_{n} \phi\left(p, x_{n}\right)+\left(1-\alpha_{n}\right) \phi\left(p, z_{n}\right) \leq \phi\left(p, x_{n}\right) .
\end{aligned}
$$

By (3.11) we see that $p \in C_{n}$. From Lemma 2.2 and $x_{n}=\Pi_{C_{n-1} \cap Q_{n-1}} x_{0}$, we have

$$
\left\langle p-x_{n}, J x_{0}-J x_{n}\right\rangle \leq 0,
$$

which implies that $p \in Q_{n}$. Hence $\Omega \subset C_{n} \cap Q_{n}$. By induction, $\Omega \subset C_{n} \cap Q_{n}$ for each $n \geq 0$. So the sequence $\left\{x_{n}\right\}$ generated by $(\diamond)$ is well defined for each $n \geq 0$.

Step 2 We prove that $\left\|w_{n}-T_{n} w_{n}\right\| \rightarrow 0,\left\|v_{n}-S_{n} v_{n}\right\| \rightarrow 0(n \rightarrow \infty)$.

Repeating the argument of Step 2 in the proof of [9, Theorem 3.1], we have $\phi\left(x_{n}, x_{m}\right) \rightarrow 0(n, m \rightarrow \infty)$. Thus $\left\{x_{n}\right\}$ is a Cauchy sequence and let $x^{*} \in C$ be its limit, that is, $x_{n} \rightarrow x^{*}(n \rightarrow \infty)$; in particular, $\left\{x_{n}\right\}$ is bounded. Using Lemma 2.3, we have

$$
\left\|x_{n}-x_{n+1}\right\| \rightarrow 0 \quad(n \rightarrow \infty) .
$$

Observe that by (3.8)-(3.11) the boundedness of $\left\{x_{n}\right\}$ implies that the sequences $\left\{u_{n}\right\},\left\{z_{n}\right\},\left\{v_{n}\right\},\left\{w_{n}\right\},\left\{y_{n}\right\}$, $\left\{T_{n} w_{n}\right\}$, and $\left\{S_{n} v_{n}\right\}$ are all bounded. Since $x_{n+1}=\Pi_{C_{n} \cap Q_{n}} x_{0} \in C_{n}$, we have

$$
\phi\left(x_{n+1}, u_{n}\right) \leq \phi\left(x_{n+1}, x_{n}\right) \rightarrow 0 \quad(n \rightarrow \infty),
$$


which together with Lemma 2.3 imply that $\left\|x_{n+1}-u_{n}\right\| \rightarrow 0(n \rightarrow \infty)$. So

$$
\left\|x_{n}-u_{n}\right\| \rightarrow 0 \quad(n \rightarrow \infty) .
$$

By Lemma 2.8(5), (3.11), (3.13) and the uniform continuity of $J$ over bounded sets, we have, for any $p \in \Omega$,

$$
\begin{aligned}
\phi\left(u_{n}, y_{n}\right) & =\phi\left(K_{r_{n}} y_{n}, y_{n}\right) \\
& \leq \phi\left(p, y_{n}\right)-\phi\left(p, K_{r_{n}} y_{n}\right) \\
& \leq \phi\left(p, x_{n}\right)-\phi\left(p, u_{n}\right) \\
& =\left\|x_{n}\right\|^{2}-\left\|u_{n}\right\|^{2}-2\left\langle p, J x_{n}-J u_{n}\right\rangle \\
& \leq\left(\left\|x_{n}-u_{n}\right\|\right)\left(\left\|x_{n}\right\|+\left\|u_{n}\right\|\right)+2\|p\|\left\|J x_{n}-J u_{n}\right\| \rightarrow 0 .
\end{aligned}
$$

Furthermore from Lemma 2.3 we have

$$
\left\|y_{n}-u_{n}\right\| \rightarrow 0 \quad(n \rightarrow \infty) .
$$

So by (3.13) and (3.14) we have

$$
\left\|y_{n}-x_{n}\right\| \rightarrow 0 \quad(n \rightarrow \infty) .
$$

From $(\diamond),(3.15)$ and and again the uniform continuity of $J$ on bounded sets, we get

$$
\left\|J y_{n}-J x_{n}\right\|=\left(1-\alpha_{n}\right)\left\|J z_{n}-J x_{n}\right\| \rightarrow 0 .
$$

Combining the above inequality and the condition (iii), we have

$$
\left\|J z_{n}-J x_{n}\right\| \rightarrow 0 \quad(n \rightarrow \infty) .
$$

Moreover since $J^{-1}$ is uniformly continuous on bounded sets, we have

$$
\left\|z_{n}-x_{n}\right\| \rightarrow 0 \quad(n \rightarrow \infty) .
$$

It follows from Lemma 2.7, (3.8) and the boundedness of $\left\{x_{n}\right\}$ and $\left\{T_{n} w_{n}\right\}$ that, for any $p \in \Omega$,

$$
\begin{aligned}
\phi\left(p, z_{n}\right)= & \phi\left(p, J^{-1}\left(\beta_{n}^{(1)} J x_{n}+\beta_{n}^{(2)} J T_{n} w_{n}+\beta_{n}^{(3)} J S_{n} v_{n}\right)\right) \\
= & \|p\|^{2}-2\left\langle p, \beta_{n}^{(1)} J x_{n}+\beta_{n}^{(2)} J T_{n} w_{n}+\beta_{n}^{(3)} J S_{n} v_{n}\right\rangle \\
& +\left\|\beta_{n}^{(1)} J x_{n}+\beta_{n}^{(2)} J T_{n} w_{n}+\beta_{n}^{(3)} J S_{n} v_{n}\right\|^{2} \\
\leq & \beta_{n}^{(1)} \phi\left(p, x_{n}\right)+\beta_{n}^{(2)} \phi\left(p, T_{n} w_{n}\right)+\beta_{n}^{(3)} \phi\left(p, S_{n} v_{n}\right)-\beta_{n}^{(1)} \beta_{n}^{(2)} g\left(\left\|J x_{n}-J T_{n} w_{n}\right\|\right) \\
\leq & \beta_{n}^{(1)} \phi\left(p, x_{n}\right)+\beta_{n}^{(2)} \phi\left(p, w_{n}\right)+\beta_{n}^{(3)} \phi\left(p, v_{n}\right)-\beta_{n}^{(1)} \beta_{n}^{(2)} g\left(\left\|J x_{n}-J T_{n} w_{n}\right\|\right) \\
\leq & \phi\left(p, x_{n}\right)-\beta_{n}^{(1)} \beta_{n}^{(2)} g\left(\left\|J x_{n}-J T_{n} w_{n}\right\|\right) .
\end{aligned}
$$

Hence from (3.16) and (3.17), we have

$$
\beta_{n}^{(1)} \beta_{n}^{(2)} g\left(\left\|J x_{n}-J T_{n} w_{n}\right\|\right) \leq \phi\left(p, x_{n}\right)-\phi\left(p, z_{n}\right) \rightarrow 0 \quad(n \rightarrow \infty) .
$$

Using the same argument, we obtain

$$
\beta_{n}^{(1)} \beta_{n}^{(3)} g\left(\left\|J x_{n}-J S_{n} v_{n}\right\|\right) \leq \phi\left(p, x_{n}\right)-\phi\left(p, z_{n}\right) \rightarrow 0 \quad(n \rightarrow \infty) .
$$

Moreover from the conditions (i), (ii) and the properties of $g$, we have

$$
\left\|J x_{n}-J T_{n} w_{n}\right\| \rightarrow 0 \quad(n \rightarrow \infty),
$$

and

$$
\left\|J x_{n}-J S_{n} v_{n}\right\| \rightarrow 0 \quad(n \rightarrow \infty) .
$$

Since $J^{-1}$ is uniformly continuous on bounded sets, we obtain

$$
\begin{aligned}
&\left\|x_{n}-T_{n} w_{n}\right\| \rightarrow 0 \quad(n \rightarrow \infty), \\
&\left\|x_{n}-S_{n} v_{n}\right\| \rightarrow 0 \quad(n \rightarrow \infty) .
\end{aligned}
$$


By (3.9) and (3.16) we have

$$
\left(1-\beta_{n}^{(1)}\right) 2 \lambda_{n}\left(\gamma-\frac{2}{c^{2}} \lambda_{n}\right)\left\|A x_{n}-A p\right\|^{2} \leq \phi\left(p, x_{n}\right)-\phi\left(p, z_{n}\right) \rightarrow 0 \quad(n \rightarrow \infty) .
$$

So from the condition (iii), we have

$$
\left\|A x_{n}-A p\right\| \rightarrow 0 \quad(n \rightarrow \infty) .
$$

From Lemmas 2.1, 2.2, 2.6, (3.20) and the fact that $\|A x\| \leq\|A x-A p\|$ for all $x \in C$ and $p \in \operatorname{VI}(C$, $A$ ), we have

$$
\begin{aligned}
\phi\left(x_{n}, v_{n}\right) & =\phi\left(x_{n}, \Pi_{C} J^{-1}\left(J x_{n}-\lambda_{n} A x_{n}\right)\right) \\
& \leq \phi\left(x_{n}, J^{-1}\left(J x_{n}-\lambda_{n} A x_{n}\right)\right) \\
& =V\left(x_{n}, J x_{n}-\lambda_{n} A x_{n}\right) \\
& \leq V\left(x_{n}, J x_{n}-\lambda_{n} A x_{n}+\lambda_{n} A x_{n}\right)-2\left\langle J^{-1}\left(J x_{n}-\lambda_{n} A x_{n}\right)-x_{n}, \lambda_{n} A x_{n}\right\rangle \\
& =\phi\left(x_{n}, x_{n}\right)+2 \lambda_{n}\left\|J^{-1}\left(J x_{n}-\lambda_{n} A x_{n}\right)-J^{-1} J x_{n}\right\|\left\|A x_{n}\right\| \\
& \leq 2 \lambda_{n}^{2} \frac{2}{c^{2}}\left\|A x_{n}\right\|^{2} \\
& \leq 2 \lambda_{n}^{2} \frac{2}{c^{2}}\left\|A x_{n}-A p\right\|^{2} \rightarrow 0 \quad(n \rightarrow \infty) .
\end{aligned}
$$

This implies that

$$
\left\|x_{n}-v_{n}\right\| \rightarrow 0 \quad(n \rightarrow \infty) .
$$

From (3.10), for any $p \in \Omega$, we have $\phi\left(p, w_{n}\right) \geq\left(1 / \beta_{n}^{(2)}\right)\left(\phi\left(p, z_{n}\right)-\left(1-\beta_{n}^{(2)}\right) \phi\left(p, x_{n}\right)\right)$, so by Lemma 2.9 and (3.8), we obtain

$$
\begin{aligned}
\phi\left(w_{n}, v_{n}\right) & =\phi\left(J_{t_{n}} v_{n}, v_{n}\right) \\
& \leq \phi\left(p, v_{n}\right)-\phi\left(p, J_{t_{n}} v_{n}\right) \\
& \leq \phi\left(p, x_{n}\right)-\phi\left(p, w_{n}\right) \\
& \leq \phi\left(p, x_{n}\right)-\left(\left(1 / \beta_{n}^{(2)}\right)\left(\phi\left(p, z_{n}\right)-\left(1-\beta_{n}^{(2)}\right) \phi\left(p, x_{n}\right)\right)\right) \\
& =\frac{1}{\beta_{n}^{(2)}}\left(\phi\left(p, x_{n}\right)-\phi\left(p, z_{n}\right)\right) \\
& \leq \frac{1}{\beta_{n}^{(2)}}\left(\left\|x_{n}\right\|^{2}-\left\|z_{n}\right\|^{2}-2\left\langle p, J x_{n}-J z_{n}\right\rangle\right) \\
& \leq \frac{1}{\beta_{n}^{(2)}}\left(\left\|x_{n}-z_{n}\right\|\left(\left\|x_{n}\right\|+\left\|z_{n}\right\|\right)+2\|p\|\left\|J x_{n}-J z_{n}\right\|\right) .
\end{aligned}
$$

Since the condition (i) implies that $\lim _{\inf } \rightarrow \infty \beta_{n}^{(2)}>0$, it follows from (3.16) and (3.22) that

$$
\lim _{n \rightarrow \infty} \phi\left(w_{n}, v_{n}\right)=0
$$

which implies that

$$
\lim _{n \rightarrow \infty}\left\|w_{n}-v_{n}\right\|=0
$$

Combining (3.21) and (3.23), we get

$$
\lim _{n \rightarrow \infty}\left\|x_{n}-w_{n}\right\|=0 .
$$

It follows from (3.18), (3.19), (3.21) and (3.24) that

$$
\begin{aligned}
&\left\|w_{n}-T_{n} w_{n}\right\| \rightarrow 0(n \rightarrow \infty), \\
&\left\|v_{n}-S_{n} v_{n}\right\| \rightarrow 0 \quad(n \rightarrow \infty) .
\end{aligned}
$$


Since $x_{n} \rightarrow x^{*}(n \rightarrow \infty)$, from (3.21) and (3.24) we have $v_{n} \rightarrow x^{*}, w_{n} \rightarrow x^{*}(n \rightarrow \infty)$. So by (3.25), we have $x^{*} \in\left(\cap_{n=0}^{\infty} F\left(T_{n}\right)\right) \cap\left(\cap_{n=0}^{\infty} F\left(S_{n}\right)\right)$.

Step 3 We show that $x^{*} \in \operatorname{VI}(C, A) \cap \operatorname{GMEP} \cap W^{-1} 0$.

Define an operator $S \subset E \times E^{*}$ by

$$
S v:= \begin{cases}A v+N_{C}(v), & v \in C \\ \emptyset, & v \notin C\end{cases}
$$

By Lemma 2.5, $S$ is maximal monotone and $S^{-1}(0)=V I(C, A)$. Let $(v, w) \in G(S)$. Since $w \in S v=$ $A v+N_{C}(v)$, we have $w-A v \in N_{C}(v)$. Moreover, $v_{n} \in C$ implies that

$$
\left\langle v-v_{n}, w-A v\right\rangle \geq 0 .
$$

On the other hand, it follows from the fact that $v_{n}=\Pi_{C} J^{-1}\left(J x_{n}-\lambda_{n} A x_{n}\right)$ and Lemma 2.2 that

$$
\left\langle v-v_{n}, J v_{n}-\left(J x_{n}-\lambda_{n} A x_{n}\right)\right\rangle \geq 0,
$$

and hence

$$
\left\langle v-v_{n}, \frac{J x_{n}-J v_{n}}{\lambda_{n}}-A x_{n}\right\rangle \leq 0 .
$$

So from (3.26) and (3.27) we obtain

$$
\begin{aligned}
\left\langle v-v_{n}, w\right\rangle & \geq\left\langle v-v_{n}, A v\right\rangle \\
& \geq\left\langle v-v_{n}, A v\right\rangle+\left\langle v-v_{n}, \frac{J x_{n}-J v_{n}}{\lambda_{n}}-A x_{n}\right\rangle \\
& =\left\langle v-v_{n}, A v-A x_{n}+\frac{J x_{n}-J v_{n}}{\lambda_{n}}\right\rangle \\
& \geq\left\langle v-v_{n}, A v-A v_{n}\right\rangle+\left\langle v-v_{n}, A v_{n}-A x_{n}\right\rangle+\left\langle v-v_{n}, \frac{J x_{n}-J v_{n}}{\lambda_{n}}\right\rangle \\
& \geq-\left\|v-v_{n}\right\|\left\|A v_{n}-A x_{n}\right\|-\left\|v-v_{n}\right\|\left\|\frac{J x_{n}-J v_{n}}{a}\right\| .
\end{aligned}
$$

Since $J$ is uniformly continuous on bounded sets and $A$ is continuous, by (3.21) and (3.28) we have $\left\langle v-x^{*}, w\right\rangle \geq$ $0(n \rightarrow \infty)$. Thus $x^{*} \in S^{-1}(0)$ and hence $x^{*} \in \operatorname{VI}(C, A)$.

Next we show that $x^{*} \in \mathrm{GMEP}=F\left(K_{r}\right)$. To see this, let

$$
H\left(u_{n}, y\right)=\Theta\left(u_{n}, y\right)+\left\langle B u_{n}, y-u_{n}\right\rangle+\varphi(y)-\varphi\left(u_{n}\right), \quad y \in C .
$$

From (3.14) and (3.15), we have $u_{n} \rightarrow x^{*}, y_{n} \rightarrow x^{*}(n \rightarrow \infty)$. Since $J$ is uniformly continuous on bounded sets, from (3.14) we have $\lim _{n \rightarrow \infty}\left\|J u_{n}-J y_{n}\right\|=0$. Therefore it follows from the assumption $r_{n} \geq c^{*}$ that $\lim _{n \rightarrow \infty} \frac{\left\|J u_{n}-J y_{n}\right\|}{r_{n}}=0$. Since $u_{n}=K_{r_{n}} y_{n}$, we have

$$
H\left(u_{n}, y\right)+\frac{1}{r_{n}}\left\langle y-u_{n}, J u_{n}-J y_{n}\right\rangle \geq 0, \quad \forall y \in C .
$$

Combining the above inequality and (A2), we get

$$
\left\|y-u_{n}\right\| \frac{\left\|J u_{n}-J y_{n}\right\|}{r_{n}} \geq \frac{1}{r_{n}}\left\langle y-u_{n}, J u_{n}-J y_{n}\right\rangle \geq-H\left(u_{n}, y\right) \geq H\left(y, u_{n}\right), \quad \forall y \in C .
$$

Taking the limit as $n \rightarrow \infty$ in the above inequality and by (A4) we have $H\left(y, x^{*}\right) \leq 0, \forall y \in C$. For any $t \in(0,1)$ and $y \in C$, define $y_{t}=t y+(1-t) x^{*} \in C$. So $H\left(y_{t}, x^{*}\right) \leq 0$. From (A1) and (A4), we have

$$
0=H\left(y_{t}, y_{t}\right) \leq t H\left(y_{t}, y\right)+(1-t) H\left(y_{t}, x^{*}\right) \leq t H\left(y_{t}, y\right),
$$


i.e., $H\left(y_{t}, y\right) \geq 0$. Thus by (A3) and letting $t \rightarrow 0$, we get $H\left(x^{*}, y\right) \geq 0, \forall y \in C$, which implies that $x^{*} \in$ GMEP.

Finally we prove that $x^{*} \in W^{-1} 0$. Since $J$ is uniformly continuous on bounded sets, from (3.23), we have

$$
\lim _{n \rightarrow \infty}\left\|J w_{n}-J v_{n}\right\|=0
$$

Since $\lim \inf _{n \rightarrow \infty} t_{n}>0$, we get

$$
\lim _{n \rightarrow \infty} \frac{1}{t_{n}}\left\|J w_{n}-J v_{n}\right\|=0
$$

Hence

$$
\left\|W_{t_{n}} v_{n}\right\|=\frac{1}{t_{n}}\left\|J v_{n}-J J_{t_{n}} v_{n}\right\|=\frac{1}{t_{n}}\left\|J v_{n}-J w_{n}\right\| \rightarrow 0 \quad(n \rightarrow \infty) .
$$

From Lemma 2.9(ii), we have $\left(w_{n}, W_{t_{n}} v_{n}\right) \in G(W)$. So by the monotonicity of $W$, for any $\left(z, z^{*}\right) \in G(W)$, we have $\left\langle z-w_{n}, z^{*}-W_{t_{n}} v_{n}\right\rangle \geq 0$ for all $n \geq 0$. Letting $n \rightarrow \infty$, we have $\left\langle z-x^{*}, z^{*}\right\rangle \geq 0$. Since $W$ is maximal monotone, $x^{*} \in W^{-1} 0$. Hence by Steps 2 and 3, we have $x^{*} \in \Omega$.

Step 4 Finally we prove that $x^{*}=\Pi_{\Omega} x_{0}$.

Since $x_{n+1}=\Pi_{C_{n} \cap Q_{n}} x_{0}$, we have

$$
\left\langle x_{n+1}-z, J x_{0}-J x_{n+1}\right\rangle \geq 0, \quad \forall z \in C_{n} \cap Q_{n} .
$$

Taking the limit in (3.29) and as $\Omega \subset C_{n} \cap Q_{n}$ for each $n \geq 0$, we obtain

$$
\left\langle x^{*}-z, J x_{0}-J x^{*}\right\rangle \geq 0, \quad \forall z \in \Omega .
$$

Therefore it follows from Lemma 2.2 that $x^{*}=\Pi_{\Omega} x_{0}$.

If $A \equiv 0$, then we have the following result from Theorem 3.1.

Corollary 3.2 Let $E$ be a real uniformly smooth and uniformly convex Banach space and $C$ be a nonempty, closed and convex subset of $E$. Let $W: E \rightrightarrows E^{*}$ be a maximal monotone operator satisfying $D(W) \subset C$ and let $J_{t}=(J+t W)^{-1} J$ for all $t>0$. Let $B: C \rightarrow E^{*}$ be a monotone continuous mapping. Let $\left\{T_{n}\right\},\left\{S_{n}\right\}$ be two countable families of weak relatively nonexpansive mappings from $C$ into itself such that $\Omega:=\left(\cap_{n=0}^{\infty} F\left(T_{n}\right)\right) \cap\left(\cap_{n=0}^{\infty} F\left(S_{n}\right)\right) \cap G M E P \cap W^{-1} 0 \neq \emptyset$. Let $\left\{r_{n}\right\} \subset\left[c^{*},+\infty\right)$ for some $c^{*}>0$ and $\left\{t_{n}\right\} \subset(0,+\infty)$ satisfy $\lim _{n \rightarrow \infty} \inf _{n \rightarrow \infty} t_{n}>0$. Let $\left\{x_{n}\right\}$ be the sequence generated by the algorithm

$$
\left\{\begin{array}{l}
x_{0} \in C, \text { chosen arbitrarily, } \\
z_{n}=J^{-1}\left(\beta_{n}^{(1)} J x_{n}+\beta_{n}^{(2)} J T_{n} J_{t_{n}} x_{n}+\beta_{n}^{(3)} J S_{n} x_{n}\right), \\
y_{n}=J^{-1}\left(\alpha_{n} J x_{n}+\left(1-\alpha_{n}\right) J z_{n}\right) \\
u_{n}=K_{r_{n}} y_{n}, \\
C_{0}=\left\{z \in C: \phi\left(z, u_{0}\right) \leq \phi\left(z, x_{0}\right)\right\}, \\
C_{n}=\left\{z \in C_{n-1} \cap Q_{n-1}: \phi\left(z, u_{n}\right) \leq \phi\left(z, x_{n}\right)\right\}, \\
Q_{0}=C, \\
Q_{n}=\left\{z \in C_{n-1} \cap Q_{n-1}:\left\langle x_{n}-z, J x_{0}-J x_{n}\right\rangle \geq 0\right\}, \\
x_{n+1}=\Pi_{C_{n} \cap Q_{n}} x_{0}, n \geq 0,
\end{array}\right.
$$

where $\left\{\beta_{n}^{(1)}\right\},\left\{\beta_{n}^{(2)}\right\},\left\{\beta_{n}^{(3)}\right\}$ and $\left\{\alpha_{n}\right\}$ are sequences in [0,1] satisfying the conditions:

(i) $\beta_{n}^{(1)}+\beta_{n}^{(2)}+\beta_{n}^{(3)}=1$ for all $n \geq 0$,

(ii) $\liminf _{n \rightarrow \infty} \beta_{n}^{(1)} \beta_{n}^{(2)}>0$,

(iii) $\liminf _{n \rightarrow \infty} \beta_{n}^{(1)} \beta_{n}^{(3)}>0$,

(iv) $\limsup _{n \rightarrow \infty} \alpha_{n}<1$. 
Then $\left\{x_{n}\right\}$ converges strongly to $\Pi_{\Omega} x_{0}$.

Proof From the proof of Theorem 3.1, (2.1) is used to prove (3.3), (3.9) and (3.21). Since $A \equiv 0, v_{n}=x_{n}$ for all $n \geq 0$. So in the uniformly smooth and uniformly convex Banach space $X$, we have $\phi\left(p, z_{n}\right) \leq \phi\left(p, x_{n}\right)$. Moreover, (3.18) and (3.19) are reduced to

$$
\left\|x_{n}-T_{n} w_{n}\right\| \rightarrow 0 \text { and }\left\|x_{n}-S_{n} x_{n}\right\| \rightarrow 0 \quad(n \rightarrow \infty) .
$$

So the condition $\lim \sup _{n \rightarrow \infty} \beta_{n}^{(1)}<1$ in the assumption (iii) of Theorem 3.1 is superfluous in this case, and the remainder of the proof follows that of Theorem 3.1.

Remark 3.3 Corollary 3.2 improves and generalizes Theorem 3.15 in [16].

If $A \equiv 0, T_{n}=T, S_{n}=S, W \equiv 0$, then we have the following result from Corollary 3.2.

Corollary 3.4 Let $E$ be a real uniformly smooth and uniformly convex Banach space and $C$ be a nonempty, closed and convex subset of $E$. Let $B: C \rightarrow E^{*}$ be a monotone continuous mapping. Let $T, S$ be two relatively weak nonexpansive mappings from $C$ into itself such that $\Omega:=F(T) \cap F(S) \cap G M E P \neq \emptyset$. Let $\left\{r_{n}\right\} \subset\left[c^{*},+\infty\right)$ for some $c^{*}>0$. Let $\left\{x_{n}\right\}$ be the sequence generated by the algorithm

$$
\left\{\begin{array}{l}
x_{0} \in C, \text { chosen arbitrarily, } \\
z_{n}=J^{-1}\left(\beta_{n}^{(1)} J x_{n}+\beta_{n}^{(2)} J T x_{n}+\beta_{n}^{(3)} J S x_{n}\right), \\
y_{n}=J^{-1}\left(\alpha_{n} J x_{n}+\left(1-\alpha_{n}\right) J z_{n}\right) \\
u_{n}=T_{r_{n}} y_{n}, \\
C_{0}=\left\{z \in C: \phi\left(z, u_{0}\right) \leq \phi\left(z, x_{0}\right)\right\}, \\
C_{n}=\left\{z \in C_{n-1} \cap Q_{n-1}: \phi\left(z, u_{n}\right) \leq \phi\left(z, x_{n}\right)\right\}, \\
Q_{0}=C, \\
Q_{n}=\left\{z \in C_{n-1} \cap Q_{n-1}:\left\langle x_{n}-z, J x_{0}-J x_{n}\right\rangle \geq 0\right\}, \\
x_{n+1}=\Pi_{C_{n} \cap Q_{n}} x_{0}, n \geq 0,
\end{array}\right.
$$

where $\left\{\beta_{n}^{(1)}\right\},\left\{\beta_{n}^{(2)}\right\},\left\{\beta_{n}^{(3)}\right\}$ and $\left\{\alpha_{n}\right\}$ are four sequences in [0,1] satisfying $\beta_{n}^{(1)}+\beta_{n}^{(2)}+\beta_{n}^{(3)}=1$ for all $n \geq 0$. The following conditions hold:

(i) $\liminf _{n \rightarrow \infty} \beta_{n}^{(1)} \beta_{n}^{(2)}>0$;

(ii) $\liminf _{n \rightarrow \infty} \beta_{n}^{(1)} \beta_{n}^{(3)}>0$;

(iii) $\lim _{\sup } \rightarrow \infty \alpha_{n}<1$.

Then $\left\{x_{n}\right\}$ converges strongly to $\Pi_{\Omega} x_{0}$.

Remark 3.5 Corollary 3.4 improves and generalizes Theorem 3.1 in [15].

Next, we prove a convergence theorem for Halpern-type iterative algorithm.

Theorem 3.6 Let $E$ be a real uniformly smooth and 2-uniformly convex Banach space (e.g., $L^{p}$ for $\left.1<p \leq 2\right)$ and $C$ be a nonempty, closed and convex subset of $E$. Let $W: E \rightrightarrows E^{*}$ be a maximal monotone operator satisfying $D(W) \subset C$ and let $J_{t}=(J+t W)^{-1} J$ for all $t>0$. Let $A: C \rightarrow E^{*}$ be a $\gamma$-inverse strongly monotone mapping, $B: C \rightarrow E^{*}$ be a monotone continuous mapping. Let $\left\{T_{n}\right\},\left\{S_{n}\right\}$ be two countable families of weak relatively nonexpansive mappings from $C$ into itself such that $\Omega:=\left(\cap_{n=0}^{\infty} F\left(T_{n}\right)\right) \cap\left(\cap_{n=0}^{\infty} F\left(S_{n}\right)\right) \cap$ $\operatorname{VI}(C, A) \cap G M E P \cap W^{-1} 0 \neq \emptyset$. Assume that $\|A x\| \leq\|A x-A p\|$ for all $x \in C$ and $p \in V I(C, A)$. Suppose that $0<a<\lambda_{n}<b=\frac{c^{2} \gamma}{2}$, where $c$ is the constant in (2.1). Let $\left\{r_{n}\right\} \subset\left[c^{*},+\infty\right)$ for some $c^{*}>0$ and $\left\{t_{n}\right\} \subset(0,+\infty)$ satisfy $\liminf _{n \rightarrow \infty} t_{n}>0$. Let $\left\{x_{n}\right\}$ be the sequence generated by the algorithm

$$
\left\{\begin{aligned}
& x_{0} \in C, \text { chosen arbitrarily, } \\
& v_{n}=\Pi_{C} J^{-1}\left(J x_{n}-\lambda_{n} A x_{n}\right) \\
& z_{n}=J^{-1}\left(\beta_{n}^{(1)} J x_{0}+\beta_{n}^{(2)} J T_{n} J_{t_{n}} v_{n}+\beta_{n}^{(3)} J S_{n} v_{n}\right), \\
& y_{n}=J^{-1}\left(\alpha_{n} J x_{n}+\left(1-\alpha_{n}\right) J z_{n}\right) \\
& u_{n}=K_{r_{n}} y_{n}, \\
& C_{0}=\left\{z \in C: \phi\left(z, u_{0}\right) \leq \phi\left(z, x_{0}\right)\right\} \\
& C_{n}=\left\{z \in C_{n-1} \cap Q_{n-1}:\right. \\
& \\
&\left.\quad \phi\left(z, u_{n}\right) \leq\left(1-\left(1-\alpha_{n}\right) \beta_{n}^{(1)}\right) \phi\left(z, x_{n}\right)+\left(1-\alpha_{n}\right) \beta_{n}^{(1)} \phi\left(z, x_{0}\right)\right\} \\
& Q_{0}=C \\
& Q_{n}=\left\{z \in C_{n-1} \cap Q_{n-1}:\left\langle x_{n}-z, J x_{0}-J x_{n}\right\rangle \geq 0\right\} \\
& x_{n+1}=\Pi_{C_{n} \cap Q_{n}} x_{0}, \quad n \geq 0
\end{aligned}\right.
$$


where $J$ is the normalized duality mapping, $\left\{\beta_{n}^{(1)}\right\},\left\{\beta_{n}^{(2)}\right\},\left\{\beta_{n}^{(3)}\right\}$ and $\left\{\alpha_{n}\right\}$ are sequences in [0,1] satisfying $\beta_{n}^{(1)}+\beta_{n}^{(2)}+\beta_{n}^{(3)}=1$ for all $n \geq 0$, and, moreover, the conditions below:

(i) $\lim _{n \rightarrow \infty} \beta_{n}^{(1)}=0$;

(ii) $\liminf _{n \rightarrow \infty} \beta_{n}^{(2)} \beta_{n}^{(3)}>0$;

(iii) $\liminf _{n \rightarrow \infty}\left(1-\alpha_{n}\right)>0$.

Then $\left\{x_{n}\right\}$ converges strongly to $\Pi_{\Omega} x_{0}$.

Proof Put $w_{n}=J_{t_{n}} v_{n}$. It is easy to see that $C_{n}$ and $Q_{n}$ are both closed and convex for each $n \geq 0$. We first show that $\Omega \subset C_{n} \cap Q_{n}$ for all $n \geq 0$.

Indeed, observe that $\Omega \subset Q_{0}=C$ and from Lemmas 2.8 and 2.9, for any $p \in \Omega$, we have

$$
\begin{aligned}
\phi\left(p, u_{0}\right) & =\phi\left(p, K_{r_{0}} y_{0}\right) \\
& \leq \phi\left(p, y_{0}\right) \\
& =\phi\left(p, J^{-1}\left(\alpha_{0} J x_{0}+\left(1-\alpha_{0}\right) J z_{0}\right)\right) \\
& \leq \alpha_{0} \phi\left(p, x_{0}\right)+\left(1-\alpha_{0}\right) \phi\left(p, z_{0}\right) \\
\phi\left(p, z_{0}\right) & =\phi\left(p, J^{-1}\left(\beta_{0}^{(1)} J x_{0}+\beta_{0}^{(2)} J T_{0} J_{t_{0}} v_{0}+\beta_{0}^{(3)} J S_{0} v_{0}\right)\right) \\
& \leq \beta_{0}^{(1)} \phi\left(p, x_{0}\right)+\beta_{0}^{(2)} \phi\left(p, J_{t_{0}} v_{0}\right)+\beta_{0}^{(3)} \phi\left(p, v_{0}\right) \\
& \leq \beta_{0}^{(1)} \phi\left(p, x_{0}\right)+\beta_{0}^{(2)} \phi\left(p, v_{0}\right)+\beta_{0}^{(3)} \phi\left(p, v_{0}\right) .
\end{aligned}
$$

By (3.3), (3.30), we obtain

$$
\phi\left(p, u_{0}\right) \leq \alpha_{0} \phi\left(p, x_{0}\right)+\left(1-\alpha_{0}\right) \phi\left(p, x_{0}\right)=\phi\left(p, x_{0}\right) .
$$

So $p \in C_{0}$. Thus $p \in C_{0} \cap Q_{0}$. Assume that $p \in C_{n-1} \cap Q_{n-1}$ The relations (3.30) and (3.8) imply that

$$
\begin{aligned}
\phi\left(p, u_{n}\right) & \leq \phi\left(p, y_{n}\right) \\
& \leq \alpha_{n} \phi\left(p, x_{n}\right)+\left(1-\alpha_{n}\right) \phi\left(p, z_{n}\right), \\
\phi\left(p, z_{n}\right) & \leq \beta_{n}^{(1)} \phi\left(p, x_{0}\right)+\beta_{n}^{(2)} \phi\left(p, T_{n} w_{n}\right)+\beta_{n}^{(3)} \phi\left(p, S_{n} v_{n}\right) \\
& \leq \beta_{n}^{(1)} \phi\left(p, x_{0}\right)+\beta_{n}^{(2)} \phi\left(p, w_{n}\right)+\beta_{n}^{(3)} \phi\left(p, v_{n}\right) \\
& \leq \beta_{n}^{(1)} \phi\left(p, x_{0}\right)+\beta_{n}^{(2)} \phi\left(p, v_{n}\right)+\beta_{n}^{(3)} \phi\left(p, v_{n}\right) \\
& \leq \beta_{n}^{(1)} \phi\left(p, x_{0}\right)+\left(1-\beta_{n}^{(1)}\right) \phi\left(p, x_{n}\right) .
\end{aligned}
$$

Hence

$$
\phi\left(p, u_{n}\right) \leq\left(1-\left(1-\alpha_{n}\right) \beta_{n}^{(1)}\right) \phi\left(p, x_{n}\right)+\left(1-\alpha_{n}\right) \beta_{n}^{(1)} \phi\left(p, x_{0}\right) .
$$

This implies $p \in C_{n}$. By the proof of Step 1 in Theorem 3.1, we have $p \in Q_{n}$ and so $p \in C_{n} \cap Q_{n}$. By induction, we have $\Omega \subset C_{n} \cap Q_{n}$ for all $n \geq 0$.

Similarly to the proof of Theorem 3.1, we have

$$
\begin{aligned}
& \lim _{n \rightarrow \infty} \phi\left(x_{n+1}, x_{n}\right)=0, \\
& \left\|x_{n+1}-x_{n}\right\|=0
\end{aligned}
$$

and the sequence $\left\{x_{n}\right\}$ is a Cauchy sequence. Let $x^{*} \in C$ be the (strong) limit of $\left\{x_{n}\right\}$. It particularly turns out that the sequences $\left\{x_{n}\right\},\left\{u_{n}\right\},\left\{y_{n}\right\},\left\{z_{n}\right\},\left\{w_{n}\right\},\left\{T_{n} w_{n}\right\}$ and $\left\{S_{n} v_{n}\right\}$ are all bounded. Since $x_{n+1} \in C_{n}$, by (3.32) and the condition (i) we have

$$
\phi\left(x_{n+1}, u_{n}\right) \leq\left(1-\left(1-\alpha_{n}\right) \beta_{n}^{(1)}\right) \phi\left(x_{n+1}, x_{n}\right)+\left(1-\alpha_{n}\right) \beta_{n}^{(1)} \phi\left(x_{n+1}, x_{0}\right) \rightarrow 0 \quad(n \rightarrow \infty) .
$$

Hence by Lemma 2.3, we obtain

$$
\lim _{n \rightarrow \infty}\left\|x_{n+1}-u_{n}\right\|=0
$$


This and (3.33) imply that

$$
\lim _{n \rightarrow \infty}\left\|x_{n}-u_{n}\right\|=0 .
$$

Since $J$ is uniformly continuous on bounded sets, we obtain

$$
\lim _{n \rightarrow \infty}\left\|J x_{n}-J u_{n}\right\|=0 .
$$

For any $p \in \Omega$, it follows from Lemma 2.7, (3.8) and the boundedness of $\left\{T_{n} w_{n}\right\}$ and $\left\{S_{n} v_{n}\right\}$ that

$$
\begin{aligned}
\phi\left(p, z_{n}\right)= & \|p\|^{2}-2\left\langle p, J^{-1}\left(\beta_{n}^{(1)} J x_{0}+\beta_{n}^{(2)} J T_{n} w_{n}+\beta_{n}^{(3)} J S_{n} v_{n}\right)\right\rangle \\
& +\left\|J^{-1}\left(\beta_{n}^{(1)} J x_{0}+\beta_{n}^{(2)} J T_{n} w_{n}+\beta_{n}^{(3)} J S_{n} v_{n}\right)\right\|^{2} \\
\leq & \|p\|^{2}-2 \beta_{n}^{(1)}\left\langle p, J x_{0}\right\rangle-2 \beta_{n}^{(2)}\left\langle p, J T_{n} w_{n}\right\rangle-2 \beta_{n}^{(3)}\left\langle p, J S_{n} v_{n}\right\rangle \\
& +\beta_{n}^{(1)}\left\|x_{0}\right\|^{2}+\beta_{n}^{(2)}\left\|T_{n} w_{n}\right\|^{2}+\beta_{n}^{(3)}\left\|S_{n} v_{n}\right\|^{2}-\beta_{n}^{(2)} \beta_{n}^{(3)} g\left(\left\|J T_{n} w_{n}-J S_{n} v_{n}\right\|\right) \\
= & \beta_{n}^{(1)} \phi\left(p, x_{0}\right)+\beta_{n}^{(2)} \phi\left(p, T_{n} w_{n}\right)+\beta_{n}^{(3)} \phi\left(p, S_{n} v_{n}\right)-\beta_{n}^{(2)} \beta_{n}^{(3)} g\left(\left\|J T_{n} w_{n}-J S_{n} v_{n}\right\|\right) \\
\leq & \beta_{n}^{(1)} \phi\left(p, x_{0}\right)+\beta_{n}^{(2)} \phi\left(p, w_{n}\right)+\beta_{n}^{(3)} \phi\left(p, v_{n}\right)-\beta_{n}^{(2)} \beta_{n}^{(3)} g\left(\left\|J T_{n} w_{n}-J S_{n} v_{n}\right\|\right) \\
\leq & \beta_{n}^{(1)} \phi\left(p, x_{0}\right)+\left(1-\beta_{n}^{(1)}\right) \phi\left(p, x_{n}\right)-\beta_{n}^{(2)} \beta_{n}^{(3)} g\left(\left\|J T_{n} w_{n}-J S_{n} v_{n}\right\|\right) .
\end{aligned}
$$

From the above inequality and (3.31), we have

$$
\begin{aligned}
\phi\left(p, u_{n}\right) \leq & \alpha_{n} \phi\left(p, x_{n}\right)+\left(1-\alpha_{n}\right)\left[\beta_{n}^{(1)}\left(\phi\left(p, x_{0}\right)-\phi\left(p, x_{n}\right)\right)\right. \\
& \left.+\phi\left(p, x_{n}\right)-\beta_{n}^{(2)} \beta_{n}^{(3)} g\left(\left\|J T_{n} w_{n}-J S_{n} v_{n}\right\|\right)\right] \\
\leq & \phi\left(p, x_{n}\right)+\left(1-\alpha_{n}\right) \beta_{n}^{(1)}\left(\phi\left(p, x_{0}\right)-\phi\left(p, x_{n}\right)\right) \\
& -\left(1-\alpha_{n}\right) \beta_{n}^{(2)} \beta_{n}^{(3)} g\left(\left\|J T_{n} w_{n}-J S_{n} v_{n}\right\|\right) .
\end{aligned}
$$

Hence

$$
\begin{aligned}
& \left(1-\alpha_{n}\right) \beta_{n}^{(2)} \beta_{n}^{(3)} g\left(\left\|J T_{n} w_{n}-J S_{n} v_{n}\right\|\right) \\
& \quad \leq \phi\left(p, x_{n}\right)-\phi\left(p, u_{n}\right)+\left(1-\alpha_{n}\right) \beta_{n}^{(1)}\left(\phi\left(p, x_{0}\right)-\phi\left(p, x_{n}\right)\right) \\
& \quad \leq\left\|x_{n}-u_{n}\right\|\left(\left\|x_{n}\right\|+\left\|u_{n}\right\|\right)+2\|p\|\left\|J x_{n}-J u_{n}\right\|+\left(1-\alpha_{n}\right) \beta_{n}^{(1)}\left(\phi\left(p, x_{0}\right)-\phi\left(p, x_{n}\right)\right) .
\end{aligned}
$$

From the conditions (i)-(iii), (3.34), (3.35) and the properties of the mapping $g$, we obtain

$$
\lim _{n \rightarrow \infty}\left\|J T_{n} w_{n}-J S_{n} v_{n}\right\|=0 .
$$

Now (3.31) together with the reasoning of (3.3) imply that

$$
\begin{aligned}
\phi\left(p, z_{n}\right) & \leq \beta_{n}^{(1)} \phi\left(p, x_{0}\right)+\beta_{n}^{(2)} \phi\left(p, v_{n}\right)+\beta_{n}^{(3)} \phi\left(p, v_{n}\right) \\
& \leq \beta_{n}^{(1)} \phi\left(p, x_{0}\right)+\left(1-\beta_{n}^{(1)}\right)\left[\phi\left(p, x_{n}\right)-2 \lambda_{n} \gamma\left\|A x_{n}-A p\right\|^{2}+\frac{4}{c^{2}} \lambda_{n}^{2}\left\|A x_{n}-A p\right\|^{2}\right] \\
& =\beta_{n}^{(1)} \phi\left(p, x_{0}\right)+\left(1-\beta_{n}^{(1)}\right) \phi\left(p, x_{n}\right)+\left(1-\beta_{n}^{(1)}\right) 2 \lambda_{n}\left(\frac{2}{c^{2}} \lambda_{n}-\gamma\right)\left\|A x_{n}-A p\right\|^{2} .
\end{aligned}
$$

From the above inequality and (3.31), we have

$$
\begin{aligned}
\phi\left(p, u_{n}\right) \leq & \alpha_{n} \phi\left(p, x_{n}\right)+\left(1-\alpha_{n}\right) \phi\left(p, z_{n}\right) \\
\leq & \alpha_{n} \phi\left(p, x_{n}\right)+\left(1-\alpha_{n}\right)\left(\beta_{n}^{(1)} \phi\left(p, x_{0}\right)+\left(1-\beta_{n}^{(1)}\right) \phi\left(p, x_{n}\right)\right. \\
& \left.+\left(1-\beta_{n}^{(1)}\right) 2 \lambda_{n}\left(\frac{2}{c^{2}} \lambda_{n}-\gamma\right)\left\|A x_{n}-A p\right\|^{2}\right) \\
= & \phi\left(p, x_{n}\right)+\left(1-\alpha_{n}\right) \beta_{n}^{(1)}\left(\phi\left(p, x_{0}\right)-\phi\left(p, x_{n}\right)\right) \\
& +\left(1-\alpha_{n}\right)\left(1-\beta_{n}^{(1)}\right) 2 \lambda_{n}\left(\frac{2}{c^{2}} \lambda_{n}-\gamma\right)\left\|A x_{n}-A p\right\|^{2},
\end{aligned}
$$


which implies that

$$
\begin{aligned}
(1- & \left.\alpha_{n}\right)\left(1-\beta_{n}^{(1)}\right) 2 \lambda_{n}\left(\gamma-\frac{2}{c^{2}} \lambda_{n}\right)\left\|A x_{n}-A p\right\|^{2} \\
\leq & \phi\left(p, x_{n}\right)-\phi\left(p, u_{n}\right)+\left(1-\alpha_{n}\right) \beta_{n}^{(1)}\left(\phi\left(p, x_{0}\right)-\phi\left(p, x_{n}\right)\right) \\
\leq & \left\|x_{n}-u_{n}\right\|\left(\left\|x_{n}\right\|+\left\|u_{n}\right\|\right)+2\|p\|\left\|J x_{n}-J u_{n}\right\| \\
& +\left(1-\alpha_{n}\right) \beta_{n}^{(1)}\left(\phi\left(p, x_{0}\right)-\phi\left(p, x_{n}\right)\right) .
\end{aligned}
$$

Hence from the conditions (i), (iii), (3.34) and (3.35), we have

$$
\lim _{n \rightarrow \infty}\left\|A x_{n}-A p\right\|^{2}=0 .
$$

From Lemmas 2.1, 2.2, 2.6, (3.37) and the fact of $\|A x\| \leq\|A x-A p\|$ for all $x \in C$ and $p \in \operatorname{VI}(C$, $A$ ), we have

$$
\begin{aligned}
\phi\left(x_{n}, v_{n}\right) & =\phi\left(x_{n}, \Pi_{C} J^{-1}\left(J x_{n}-\lambda_{n} A x_{n}\right)\right) \\
& \leq \phi\left(x_{n}, J^{-1}\left(J x_{n}-\lambda_{n} A x_{n}\right)\right) \\
& =V\left(x_{n}, J x_{n}-\lambda_{n} A x_{n}\right) \\
& \leq V\left(x_{n}, J x_{n}-\lambda_{n} A x_{n}+\lambda_{n} A x_{n}\right)-2\left\langle J^{-1}\left(J x_{n}-\lambda_{n} A x_{n}\right)-x_{n}, \lambda_{n} A x_{n}\right\rangle \\
& =\phi\left(x_{n}, x_{n}\right)+2 \lambda_{n}\left\|J^{-1}\left(J x_{n}-\lambda_{n} A x_{n}\right)-J^{-1} J x_{n}\right\|\left\|A x_{n}\right\| \\
& \leq 2 \lambda_{n}^{2} \frac{2}{c^{2}}\left\|A x_{n}\right\|^{2} . \\
& \leq 2 \lambda_{n}^{2} \frac{2}{c^{2}}\left\|A x_{n}-A p\right\|^{2} \rightarrow 0 \quad(n \rightarrow \infty) .
\end{aligned}
$$

This implies that

$$
\left\|x_{n}-v_{n}\right\| \rightarrow 0 \quad(n \rightarrow \infty) .
$$

From (3.31), (3.34)-(3.35), Lemma 2.8 and the conditions (i) and (iii), for any $p \in \Omega$ we have

$$
\begin{aligned}
\phi\left(u_{n}, y_{n}\right)= & \phi\left(K_{r_{n}} y_{n}, y_{n}\right) \\
\leq & \phi\left(p, y_{n}\right)-\phi\left(p, u_{n}\right) \\
\leq & \alpha_{n} \phi\left(p, x_{n}\right)+\left(1-\alpha_{n}\right)\left[\beta_{n}^{(1)} \phi\left(p, x_{0}\right)+\left(1-\beta_{n}^{(1)}\right) \phi\left(p, x_{n}\right)\right]-\phi\left(p, u_{n}\right) \\
= & \phi\left(p, x_{n}\right)-\phi\left(p, u_{n}\right)+\left(1-\alpha_{n}\right) \beta_{n}^{(1)}\left(\phi\left(p, x_{0}\right)-\phi\left(p, x_{n}\right)\right) \\
\leq & \left\|x_{n}-u_{n}\right\|\left(\left\|x_{n}\right\|+\left\|u_{n}\right\|\right)+2\|p\|\left\|J x_{n}-J u_{n}\right\| \\
& +\left(1-\alpha_{n}\right) \beta_{n}^{(1)}\left(\phi\left(p, x_{0}\right)-\phi\left(p, x_{n}\right)\right) \rightarrow 0 \quad(n \rightarrow \infty) .
\end{aligned}
$$

So

$$
\lim _{n \rightarrow \infty}\left\|u_{n}-y_{n}\right\|=0
$$

It follows from (3.34) and (3.39) that

$$
\lim _{n \rightarrow \infty}\left\|x_{n}-y_{n}\right\|=0
$$

Since $J$ is uniformly continuous on bounded sets,

$$
\lim _{n \rightarrow \infty}\left\|J x_{n}-J y_{n}\right\|=0 .
$$

Since $y_{n}=J^{-1}\left(\alpha_{n} J x_{n}+\left(1-\alpha_{n}\right) J z_{n}\right)$, i.e., $J y_{n}=\alpha_{n} J x_{n}+\left(1-\alpha_{n}\right) J z_{n}$. Now by virtue of (3.40) and the condition (iii), we have

$$
\left\|J x_{n}-J z_{n}\right\|=\frac{1}{1-\alpha_{n}}\left\|J y_{n}-J x_{n}\right\| \rightarrow 0 \quad(n \rightarrow \infty) .
$$


Since $J^{-1}$ is uniformly continuous on bounded sets, we get

$$
\lim _{n \rightarrow \infty}\left\|x_{n}-z_{n}\right\|=0 .
$$

By virtue of (3.38) and (3.42), we have

$$
\lim _{n \rightarrow \infty}\left\|z_{n}-v_{n}\right\|=0
$$

Since $J$ is uniformly continuous on bounded sets, we obtain

$$
\lim _{n \rightarrow \infty}\left\|J z_{n}-J v_{n}\right\|=0
$$

Since $z_{n}=J^{-1}\left(\beta_{n}^{(1)} J x_{0}+\beta_{n}^{(2)} J T_{n} w_{n}+\beta_{n}^{(3)} J S_{n} v_{n}\right), J z_{n}=\beta_{n}^{(1)} J x_{0}+\beta_{n}^{(2)} J T_{n} w_{n}+\beta_{n}^{(3)} J S_{n} v_{n}$; it follows that

$$
\begin{aligned}
\left\|J z_{n}-J v_{n}\right\| & =\left\|\beta_{n}^{(1)}\left(J x_{0}-J v_{n}\right)+\beta_{n}^{(2)}\left(J T_{n} w_{n}-J v_{n}\right)+\beta_{n}^{(3)}\left(J S_{n} v_{n}-J v_{n}\right)\right\| \\
& \geq\left\|\beta_{n}^{(2)}\left(J T_{n} w_{n}-J v_{n}\right)+\beta_{n}^{(3)}\left(J S_{n} v_{n}-J v_{n}\right)\right\|-\beta_{n}^{(1)}\left\|J x_{0}-J v_{n}\right\|
\end{aligned}
$$

Combining the last inequality, (3.43) and the condition (i), we obtain

$$
\left\|\beta_{n}^{(2)}\left(J T_{n} w_{n}-J v_{n}\right)+\beta_{n}^{(3)}\left(J S_{n} v_{n}-J v_{n}\right)\right\| \leq\left\|J z_{n}-J v_{n}\right\|+\beta_{n}^{(1)}\left\|J x_{0}-J v_{n}\right\| \rightarrow 0 .
$$

On the other hand, by using the property of norm $\|\cdot\|$, we have

$$
\begin{aligned}
& \left\|\beta_{n}^{(2)}\left(J T_{n} w_{n}-J v_{n}\right)+\beta_{n}^{(3)}\left(J S_{n} v_{n}-J v_{n}\right)\right\| \\
& =\left\|\beta_{n}^{(2)}\left(J T_{n} w_{n}-J v_{n}\right)+\beta_{n}^{(3)}\left(J S_{n} v_{n}-J v_{n}\right)+\beta_{n}^{(3)}\left(J T_{n} w_{n}-J v_{n}\right)-\beta_{n}^{(3)}\left(J T_{n} w_{n}-J v_{n}\right)\right\| \\
& =\left\|\left(\beta_{n}^{(2)}+\beta_{n}^{(3)}\right)\left(J T_{n} w_{n}-J v_{n}\right)+\beta_{n}^{(3)}\left(J S_{n} v_{n}-J T_{n} w_{n}\right)\right\| \\
& \geq\left\|\left(\beta_{n}^{(2)}+\beta_{n}^{(3)}\right)\left(J T_{n} w_{n}-J v_{n}\right)\right\|-\beta_{n}^{(3)}\left\|J S_{n} v_{n}-J T_{n} w_{n}\right\| .
\end{aligned}
$$

From (3.36), (3.44) and the above inequality, we obtain

$$
\lim _{n \rightarrow \infty}\left\|\left(\beta_{n}^{(2)}+\beta_{n}^{(3)}\right)\left(J T_{n} w_{n}-J v_{n}\right)\right\|=\lim _{n \rightarrow \infty}\left\|\left(1-\beta_{n}^{(1)}\right)\left(J T_{n} w_{n}-J v_{n}\right)\right\|=0,
$$

which together with the condition (i) imply that

$$
\lim _{n \rightarrow \infty}\left\|J T_{n} w_{n}-J v_{n}\right\|=0 .
$$

Since $J^{-1}$ is uniformly continuous on bounded sets, we have

$$
\lim _{n \rightarrow \infty}\left\|T_{n} w_{n}-v_{n}\right\|=0 .
$$

Similarly, we can prove that

$$
\lim _{n \rightarrow \infty}\left\|S_{n} v_{n}-v_{n}\right\|=0 .
$$

For any $p \in \Omega$, it follows from (3.8) and (3.31) that

$$
\begin{aligned}
\phi\left(p, z_{n}\right) & \leq \beta_{n}^{(1)} \phi\left(p, x_{0}\right)+\beta_{n}^{(2)} \phi\left(p, w_{n}\right)+\beta_{n}^{(3)} \phi\left(p, v_{n}\right) \\
& \leq \beta_{n}^{(1)} \phi\left(p, x_{0}\right)+\beta_{n}^{(2)} \phi\left(p, w_{n}\right)+\beta_{n}^{(3)} \phi\left(p, x_{n}\right) .
\end{aligned}
$$


By Lemma 2.9, (3.8), (3.41)-(3.42), (3.47) and the conditions (i) and (ii), we obtain

$$
\begin{aligned}
\phi\left(w_{n}, v_{n}\right)= & \phi\left(J_{t_{n}} v_{n}, v_{n}\right) \\
\leq & \phi\left(p, v_{n}\right)-\phi\left(p, J_{t_{n}} v_{n}\right) \\
\leq & \phi\left(p, x_{n}\right)-\phi\left(p, w_{n}\right) \\
\leq & \phi\left(p, x_{n}\right)-\frac{1}{\beta_{n}^{2}}\left(\phi\left(p, z_{n}\right)-\beta_{n}^{(1)} \phi\left(p, x_{0}\right)-\beta_{n}^{(3)} \phi\left(p, x_{n}\right)\right) \\
= & \frac{1}{\beta_{n}^{(2)}}\left(\phi\left(p, x_{n}\right)-\phi\left(p, z_{n}\right)\right)+\frac{\beta_{n}^{(1)}}{\beta_{n}^{(2)}}\left(\phi\left(p, x_{0}\right)-\phi\left(p, x_{n}\right)\right) \\
\leq & \frac{1}{\beta_{n}^{(2)}}\left(\left\|x_{n}-z_{n}\right\|\left(\left\|x_{n}\right\|+\left\|z_{n}\right\|\right)+2\|p\|\left\|J x_{n}-J z_{n}\right\|\right) \\
& +\frac{\beta_{n}^{(1)}}{\beta_{n}^{(2)}}\left(\phi\left(p, x_{0}\right)-\phi\left(p, x_{n}\right)\right) \rightarrow 0 \quad(n \rightarrow \infty),
\end{aligned}
$$

which together with Lemma 2.3 imply that

$$
\lim _{n \rightarrow \infty}\left\|w_{n}-v_{n}\right\|=0 .
$$

From (3.45) and (3.48), we obtain

$$
\lim _{n \rightarrow \infty}\left\|T_{n} w_{n}-w_{n}\right\|=0 .
$$

Since $x_{n} \rightarrow x^{*}$ as $n \rightarrow \infty$, by (3.38) and (3.48), we have $v_{n} \rightarrow x^{*}$ and $w_{n} \rightarrow x^{*}$ as $n \rightarrow \infty$. So by (3.46) and (3.49), we conclude that $x^{*} \in \cap_{n=0}^{\infty} F\left(T_{n}\right) \cap \cap_{n=0}^{\infty} F\left(S_{n}\right)$.

Similarly to the proof of Step 3 in Theorem 3.1, we have $x^{*} \in \operatorname{VI}(C, A) \cap \operatorname{GMEP} \cap W^{-1} 0$. So $x^{*} \in \Omega$. Similarly to the proof of Step 4 in Theorem 3.1, we get $x^{*}=\Pi_{\Omega} x_{0}$.

If $A \equiv 0, W \equiv 0$, then similarly to the proof of Corollary 3.2, we find that the uniform smoothness and 2-uniform convexity of $E$ can be weakened to uniform smoothness and uniform convexity of $E$. So from Theorem 3.6, we have the following corollary.

Corollary 3.7 Let $E$ be a real uniformly smooth and uniformly convex Banach space and $C$ be a nonempty, closed and convex subset of E. Let $B: C \rightarrow E^{*}$ be a monotone continuous mapping. Let $\left\{T_{n}\right\},\left\{S_{n}\right\}$ be two countable families of weak relatively nonexpansive mappings from $C$ into itself such that $\Omega:=\left(\cap_{n=0}^{\infty} F\left(T_{n}\right)\right) \cap$ $\left(\cap_{n=0}^{\infty} F\left(S_{n}\right)\right) \cap G M E P \neq \emptyset$. Suppose that $0<a<\lambda_{n}<b=\frac{1}{2} c^{2} \gamma$, where $c$ is the constant in (2.1). Let $\left\{r_{n}\right\} \subset\left[c^{*},+\infty\right)$ for some $c^{*}>0$. Let $\left\{x_{n}\right\}$ be the sequence generated by the following algorithm

$$
\left\{\begin{aligned}
& x_{0} \in C, \text { chosen arbitrarily, } \\
& z_{n}=J^{-1}\left(\beta_{n}^{(1)} J x_{0}+\beta_{n}^{(2)} J T_{n} x_{n}+\beta_{n}^{(3)} J S_{n} x_{n}\right), \\
& y_{n}=J^{-1}\left(\alpha_{n} J x_{n}+\left(1-\alpha_{n}\right) J z_{n}\right) \\
& u_{n}=K_{r_{n}} y_{n}, \\
& C_{0}=\left\{z \in C: \phi\left(z, u_{0}\right) \leq \phi\left(z, x_{0}\right)\right\} \\
& C_{n}=\left\{z \in C_{n-1} \cap Q_{n-1}:\right. \\
&\left.\quad \phi\left(z, u_{n}\right) \leq\left(1-\left(1-\alpha_{n}\right) \beta_{n}^{(1)}\right) \phi\left(z, x_{n}\right)+\left(1-\alpha_{n}\right) \beta_{n}^{(1)} \phi\left(z, x_{0}\right)\right\}, \\
& Q_{0}=C, \\
& Q_{n}=\left\{z \in C_{n-1} \cap Q_{n-1}:\left\langle x_{n}-z, J x_{0}-J x_{n}\right\rangle \geq 0\right\}, \\
& x_{n+1}=\Pi_{C_{n} \cap Q_{n} x_{0}, n \geq 0,}
\end{aligned}\right.
$$

where $J$ is the normalized duality mapping, $\left\{\beta_{n}^{(1)}\right\},\left\{\beta_{n}^{(2)}\right\},\left\{\beta_{n}^{(3)}\right\}$ and $\left\{\alpha_{n}\right\}$ are sequences in [0,1] satisfying $\beta_{n}^{(1)}+\beta_{n}^{(2)}+\beta_{n}^{(3)}=1$ for all $n \geq 0$, and the following conditions:

(i) $\lim _{n \rightarrow \infty} \beta_{n}^{(1)}=0$;

(ii) $\liminf _{n \rightarrow \infty} \beta_{n}^{(2)} \beta_{n}^{(3)}>0$;

(iii) $\lim \inf _{n \rightarrow \infty}\left(1-\alpha_{n}\right)>0$. 
Then $\left\{x_{n}\right\}$ converges strongly to $\Pi_{\Omega} x_{0}$.

Remark 3.8 Corollary 3.7 improves and extends Theorem 3.19 in [8] and Theorem 3.3 in [10].

Acknowledgments This work was done during the first and third authors' visit to the Research Center for Nonlinear Analysis and Discrete Mathematics at the National Sun Yat-sen University. The second author extends his appreciation to the Deanship of Scientific Research at King Saud University for funding the work through a visiting professorship program.

Open Access This article is distributed under the terms of the Creative Commons Attribution License which permits any use, distribution, and reproduction in any medium, provided the original author(s) and the source are credited.

\section{References}

1. Alber, Ya.: Metric and generalized projection operators in Banach spaces: Properties and applications. In: Kartsatos, A.G. (ed.) Theory and Applications of Nonlinear Operators of Accretive and Monotone Type. Lecture Notes in Pure and Appl. Math., vol. 178, pp. 15-50. Dekker, New York (1996)

2. Blum, E.; Oettli, W.: From optimization and variational inequalities to equilibrium problems. Math. Student 63, 123-145 (1994)

3. Butanriu, D.; Reich, S.; Zaslavski, A.J.: Asymtotic behavior of relatively nonexpansive operators in Banach spaces. J. Appl. Anal. 7, 151-174 (2001)

4. Butanriu, D.; Reich, S.; Zaslavski, A.J.: Weakly convergence of orbits of nonlinear operators in reflexive Banach spaces. Numer. Funct. Anal. Optim. 24, 489-508 (2003)

5. Ceng, L.C.; Yao, J.C.: A hybrid iterative scheme for mixed equilibrium problems and fixed point problems. J. Comput. Appl. Math. 214, 186-201 (2008)

6. Cho, Y.J.; Zhou, H.Y.; Guo, G.: Weak and strong convergence theorems for three-step iterations with errors for asymptotically nonexpansive mappings. Comput. Math. Appl. 47, 707-717 (2004)

7. Kamimura, S.; Takahashi, W.: Strong convergence of proximal-type algorithm in a Banach space. SIAM J. Optim. 13, 938-945 (2002)

8. Kamimura, S.; Kohsaka, F.; Takahashi, W.: Weak and strong convergence theorem for maximal monotone operators in a Banach space. Set-Valued Anal. 12, 417-429 (2004)

9. Kohsaka, F.; Takahashi, W.: Strong convergence of an iterative sequence for maximal monotone operators in a Banach space. Abstr. Appl. Anal. 3, 239-249 (2004)

10. Kohsaka, F.; Takahashi, W.: Existence and approximation of fixed points of firmly nonexpansive-type mappings in Banach spaces. SIAM J. Optim. 19(2), 824-835 (2008)

11. Pascali, D.; Sburlan, S.: Nonlinear Mappings of Monotone Type, Editura Academiae. Bucaresti, Romania (1978)

12. Reich, S.: A weak convergence theorem for the alternating method with Bergman distance. In: Kartsatos, A.G. (ed.) Theory and Applications of Nonlinear Operators of Accretive and Monotone Type. Lecture Notes in Pure and Appl. Math., vol. 178, pp. 313-318. Dekker, New York (1996)

13. Rockafellar, R.T.: On the maximality of sums of nonlinear monotone operators. Trans. Am. Math. Soc. 149, 75-88 (1970)

14. Rockafellar, R.T.: Monotone operators and the proximal point algorithm. SIAM J. Control Optim. 14, 877-898 (1976)

15. Su, Y.F.; Wang, Z.M.; Xu, H.K.: Strong convergence theorems for a common fixed point of two hemi-relatively nonexpansive mappings. Nonlinear Anal. 71, 5616-5628 (2009)

16. Su, Y.F.; Xu, H.K.; Zhang, X.: Strong convergence theorems for two countable families of weak relatively nonexpansive mappings and applications. Nonlinear Anal. 73, 3890-3906 (2010)

17. Takahashi, W.: Nonlinear Functional Analysis. Kindikagaku, Tokyo (1988) (in Japanese)

18. Takahashi, S.; Takahashi, W.: Strong convergence theorem for a generalized equilibrium problem and a nonexpansive mapping in a Hilbert space. Nonlinear Anal. 69, 1025-1033 (2008)

19. Takahashi, W.; Zembayashi, K.: Strong and weak convergence theorems for equilibrium problems and relatively nonexpansive mappings in Banach spaces. Nonlinear. Anal. 70, 45-57 (2009)

20. Wang, Y.Q.; Zeng, L.C.: Hybrid projection method for generalized mixed equilibrium problems, variational inequality problems, and fixed point problems in Banach spaces. Appl. Math. Mech. Engl. Ed. 32(2), 251-264 (2011)

21. Xu, H.K.: Inequalities in Banach spaces with applications. Nonlinear Anal. 16, 1127-1138 (1991)

22. Zegeye, H.; Shahzad, N.: Strong convergence theorems for monotone mappings and relatively weak nonexpansive mappings. Nonlinear Anal. 70, 2707-2716 (2009)

23. Zhang, S.S.: Generalized mixed equilibrium problem in Banach spaces. Appl. Math. Mech. Engl. Ed. 30(9), 1105-1112 (2009) 